\title{
Managing Consumer Behavior toward On-Time Return of the Waste \\ Electrical and Electronic Equipment: A Game Theoretic Approach
}

\section{Mostafa Sabbaghi}

Research Assistant, Industrial and Systems Engineering Department University at Buffalo, SUNY, Buffalo, NY, 14260

\section{Sara Behdad * Corresponding Author}

Assistant Professor, Industrial and Systems Engineering, Mechanical and Aerospace Engineering University at Buffalo, SUNY, Buffalo, NY, 14260

Tel: 716-645-5914, Fax: 7166452883

\section{Jun Zhuang}

Associate Professor, Industrial and Systems Engineering Department University at Buffalo, SUNY, Buffalo, NY, 14260

\begin{abstract}
Increasing the collection rate of used products depends on how end users perceive the value of a used product and benefits of returning it. It is empirically proven that consumers tend to store their unwanted electronic devices after the last time of usage. In this paper, an Original Equipment Manufacturer (OEM) - taking the responsibility of remanufacturing-launches a take-back program to acquire consumers' used products for remanufacturing activities. The consumers' decision about when to return the End-of-Use/Life (EoU/L) products and manufacturer's decision for the amount of incentive offered to consumers are incorporated into a theoretic game framework. The equilibrium solutions are provided in the presence of heterogeneous and homogeneous consumers. Some managerial insights are derived from the one-way and two-way sensitivity analyses. It has been shown that convenience of services, consumers' tendency to overvalue the unwanted products, the usage time of electronics, consumers' perceptions of products' obsolescence, and the remarketability of refurbished products all affect the strategic decisions made by both stakeholder groups.
\end{abstract}

Keywords: WEEE, Ease-of-Return, Consumer Post-purchase Behavior, Game Theory 


\title{
Managing Consumer Behavior toward On-Time Return of the Waste \\ Electrical and Electronic Equipment: A Game Theoretic Approach
}

\begin{abstract}
Increasing the collection rate of used products depends on how end users perceive the value of a used product and benefits of returning it. It is empirically proven that consumers tend to store their unwanted electronic devices after the last time of usage. In this paper, an Original Equipment Manufacturer (OEM) - taking the responsibility of remanufacturing - launches a take-back program to acquire consumers' used products for remanufacturing activities. The consumers' decision about when to return the End-ofUse/Life (EoU/L) products and manufacturer's decision for the amount of incentive offered to consumers are incorporated into a theoretic game framework. The equilibrium solutions are provided in the presence of heterogeneous and homogeneous consumers. Some managerial insights are derived from the one-way and two-way sensitivity analyses. It has been shown that convenience of services, consumers' tendency to overvalue the unwanted products, the usage time of electronics, consumers' perceptions of products' obsolescence, and the remarketability of refurbished products all affect the strategic decisions made by both stakeholder groups.
\end{abstract}

Keywords: WEEE, Ease-of-Return, Consumer Post-purchase Behavior, Game Theory

\section{Introduction}

Governmental agencies and environmental protection organizations have started emphasizing the need for proper collection and disposal of discarded waste, especially electronic and electrical devices that contain chemical hazards and toxic substances. The waste from electrical and electronic equipment (WEEE) is growing faster than ever before. According to the latest estimates, almost 40 million tons of WEEE are generated annually worldwide [1]. However, much of this WEEE is still functional or slightly defective and can be reused in future life cycles [2].

To control the flow of WEEE, various provisions have been legislated for all stakeholder groups. Previous legislation has mainly focused on urging Original Equipment Manufacturers (OEMs) to take responsibility for managing the return stream of their EoU/L products [3]. Recently, a few legislative laws have been enacted to prevent consumers from throwing EoU/L items away or simply putting them in the trash [4]. However, it seems that the WEEE problem still remains and more supportive actions are required besides the laws enforced by national authorities.

Collecting used devices is particularly problematic for remanufacturers since collection basically depends on consumers' decisions on when and how they want to discard their WEEE. Consumers commonly store obsolete devices for a relatively long time [5]. The inconvenient access to take-back programs and collection facilities [6], the lack of sufficient incentives [7], the lack of awareness about the formal recovery systems [8], and the possibility of future reuse [9] are among the factors that often prevent consumers from on-time return of their used devices.

The remanufacturing cost is highly dependent upon the condition of used devices and ability to be resold in the market, which decreases as technology progresses. Overall, consumers do not have positive attitudes toward purchasing relatively old refurbished products [10]. Therefore, on-time return of used devices in good condition and viable technology helps remanufacturers make product take-back systems profitable [11]. To motivate consumer participation in a take-back system, it is 
important to understand what consumers care about most when they decide to participate in take-back programs.

Most often, refurbishers' and consumers' interests are not in-line with one another and are sometimes even in conflict. The benefit to each stakeholder depends on the actions of each stakeholder group. In this particular context, remanufacturers aim to reduce consumers' productstoring behavior and consumers prefer to keep their used devices in storage because of high transaction costs and endowment effects. Consumers are generally averse to losing possession of a product in exchange for a monetary incentive, known as loss aversion or endowment effect [12].

The objective of this paper is to define the level of monetary incentive that should be offered to consumers to reduce the product storing behavior and increase consumers' participation in take-back systems. This study aims to provide new insights into managing take-back programs. The consumers' preferences and attitudes toward take-back programs are incorporated into the economic analysis of the remanufacturing operations using a game-theory formulation. In the proposed game-theoretic model, the OEM acts as remanufacturer in a closed-loop supply chain, and aims to control the rate and timing of returns by offering an incentive reward to consumers.

The rest of this paper is organized as follows: Section 2 provides the review of related literature. Section 3 describes the research idea in the form of a game-theoretic model. The equilibrium solutions for the game model are derived assuming heterogeneous and homogeneous consumer behaviors under two separate cases. The results and related insights are discussed through a numerical example in Section 4. The concluding remarks, the study limitations, and future research directions are listed in Section 5. Finally, Appendices A1-A3 illustrate proof of the theorems.

\section{Literature Review}

Controlling and handling the uncertain rate and condition of returns are the steps toward increasing profitability of recovery operations. Passively accepting any returned product with uncertain quality and quantity brings undesirable extra sorting processes which lead to complexity and unprofitability of recovery activities [13]. In addition to quantity and quality of returns, the timing of return highly impacts the potential future remarketability of remanufactured products [14].

The acquisition of used products and manufacturing/remanufacturing operations management have been addressed extensively in the literature of closed-loop supply chain and reverse logistics. Heretofore, the literature can be divided into two substantive categories. The first group of studies have been directed at harmonizing the operations of a hybrid system where an uncertain inflow of used product arrives at the system. They aim to tackle the problems related in particular to the uncertain quantity and quality of returns. Optimal controlling of manufacturing/remanufacturing production rates to minimize inventory costs under uncertainty [15], deciding on product substitution to avoid shortage cost [16], scheduling the production of new and remanufacturable returned products [17], and quantifying the environmental effects of multi-cycle production-inventory system of manufacturing-remanufacturing operations [18] are some examples from this line of research. Besides handling uncertainties in the operations management, other issues have been addressed as well. Modelling the accumulated used products' collection from depots as a vehicle-routing problem [19], assessing the impact of governmental supportive policies on the performance of recovery systems [20], modelling agents' interactions (e.g., product design and pricing strategies) in a competitive market of new and remanufactured products [21] are just a few examples of what can be found in the literature.

The basic question targeted in the second group of studies is how to acquire the used products to make recovery activities more profitable. In other words, how to control and reduce the undesirable 
uncertainties in returned items. It reveals that consumers have an inherent aversion toward returning their EoU/L products [22]. Therefore, an incentive price is presumably offered to incentivize consumers to participate in take-back programs. As a pioneer study, Guide et al. [23] proposed an econometric model where the acquisition rate of used products depends on the offered take-back price and the selling price affects the consumers' demand for remanufactured products. They developed a framework to find the optimal prices and profitability of the recovery activities. Following this study, other researchers consider the incentive-based acquisition strategy as a product return controlling policy in their models [24], [25]. Some manufacturers would rather rebate the consumers whenever they intend to replace the old product with a new one. Ray et al. [26] studied how different pricing and rebate strategies impact the profit of manufacturing and remanufacturing activities. Based on the remaining life of the currently owned products, the consumers decide to replace them. In this paper, the age-dependent or independent rebate policies are compared to the case when a uniform price is offered to consumers.

There is no doubt that a fair buy-back price [27], the convenience of taking the EoU/L items back [6], and consumers' awareness about the environmental effects [28] shorten the storage time; however, what consumers perceive about the take-back program and the condition of their EoU/L items mainly determine their decisions. The question of how to motivate consumers to return their EoU/L items on-time remains. Even in the case of obsolete products, consumers often tend to store them for a period of time after the last time of usage [5]. Therefore, how do consumers value items and the offered incentive? And do they immediately return the EoU/L items after the last time of use?

A recent stream of literature focuses on quantifying the consumers' intention to return used devices and their attitudes toward their items. In these few studies, the incentive value is not the only decision factor for returning the items. In a recent-published paper, Jena and Sarmah [29] found that the perceived benefit and the social awareness of remanufacturing activities augment the consumers' return intention. On the other hand, the consumers' perceived risk of losing an old product and obtaining a new one may decrease the return intention. In another study [5], it reveals that if consumers use a product for a longer time, they are less likely to store it. The product return stream is uncertain in terms of the time of return, quantity, and quality [30]. Agrawal et al. [31] applied the Graphical Evaluation and Review Technique to predict the return stream of used products. The probability of consumers' actions (e.g., reuse, disposal, store, taking the used product back) is estimated by conducting a survey. In another attempt to capture post-purchase behavior, Budijati et al. [32] conducted a survey-based study to find the most likely choice in terms of storage or donation that consumers make for used cellphones.

Throughout the literature of handling uncertain returns, the strategic decision making models such as game-theoretic approaches have been used to control and manage all sources of uncertainty [33]. The EoU/L products can be collected according to a contract between manufacturers and retailers. What seems essential, then, is a mechanism to coordinate the activities of reverse logistics' members. Guo and Ma [34] studied the setting of this mechanism as a stackelberg model. The manufacturer, who leads the game, determines the selling price of remanufactured products as well as of the price of used products collected by the retailer. On the other hand, the retailer, who is the follower in the game, is being aware of manufacturer's decision and determines the optimal amount of take-back price and also the price of remanufactured products for consumers. Following this paper, Ma and Wang [35] solved the game as a Nash equilibrium for the case that manufacturers and retailers have the same power to make decisions. Zhang et al. [36] devolved a game-theoretic model to optimally design a contract between a manufacturer and a retailer to collect unwanted products. The information 
about the cost of collection is not accessible to the manufacturer. Also, the retailer is merely aware of this information.

In another study [37], a manufacturer and a remanufacturer of toner cartridges determine optimal pricing policies for the cooperation and competition schemes. It is found that competition would result in a higher profit than cooperation; however, the collection rate of product might be lower. Developing a three-stage game-theoretic model, Sheu and Chen [38] implied that how government intervention such as taxation and subsidization policies can serve to promote the supply chain of green products. However, in these papers, the role of consumers and the attitudes that they have towards collection of unwanted products is not incorporated into the models. Controlling the timing, volume, and quality of returns is not possible unless consumers' behavior is understood.

Few papers can be found in the literature that do include the role of consumer behavior in trade-in remanufacturing. Zhang and Zhang [39] addressed the impact of strategic and myopic consumers in profitability of trade-in remanufacturing. Myopic consumers only consider the current attainable utility, whereas the strategic consumers take the future anticipated utility into account in decisionmaking process. In such trade-in programs that rebates are offered to consumers to return the old product and replace it with new one, the strategic consumers are inclined to pay a higher first-period price for a new released product compared to the myopic consumers. Comparing these types of behavior in a game-theoretic model, they concluded that the expected profits of trade-in remanufacturing would be higher in presence of strategic consumers, compared to myopic consumers. However, trade-in remanufacturing with strategic consumers may result in higher environmental impact since production increases without improving the social side. In a paper by $\mathrm{Wu}$ [40], the consumers' return decision is formulated using the concept behind the Hotelling model, in which a consumer may decide to return a product based on the distance from the collector location, transportation cost, and the amount of incentive offered by each collector. The consumers' return utility is defined as a linear function of the mentioned parameters. Recently, Genc and De Giovanni [41] incorporated the consumers' return behavior into a two-period model of closed-loop supply chain. In their study, the return rate is linked to the value and quality of the return, however, it has been assumed that all consumers behave homogeneously.

The current paper differs from the discussed literature in several ways; to the best of our knowledge, this paper is the first to include the strategic decisions made by individual consumers in take-back or trade-in systems based on consumers' perception about the condition of the product, amount of incentives, and trade-in convenience; we consider consumers' homogeneous and heterogeneous attitudes towards storing the EoU/L products and return time; also the impact of product age on profitability of remanufacturing activities is included in the model. A utility function - representing the consumers' preference to keep storing the EoU/L items - is used and a game theory model is formulated to provide the insights required for remanufacturers who incentivize consumers.

\section{The Game Model}

The life cycles of electronic products are getting shorter over time, i.e., new generations of products are introduced frequently in the market to entice consumers to purchase more. As a consequence of this planned technical obsolescence, millions of tons of electronics go out of use every year; however, a large portion of these products are still reusable [42] and can be returned to environmentally conscious programs [43]. Product take-back legislation makes the manufacturers liable for collection and proper recovery of WEEE [44]. Thus, the manufacturers need to come up with an effective way to collect and recover used items. Fig. 1 illustrates a typical tack-back system 
flowchart. There might be differences among various programs, but the similarities are profound and predominant.

The number of trade-in websites or take-back programs launched by original manufacturers and third party business corporations is considerable (e.g., Apple, Dell, Gazelle, BestBuy, and Amazon). The programs often offer either pre-paid shipping or in-store drop-offs to encourage consumers to take back their unwanted products. The trade-in transactions can be done via an online interface, although consumers could return the products in retail stores as well. In online services, consumers are first asked to select the type of product and some other associated information. For example, for the case of cell phones, consumers must indicate whether the phone is unlocked or restricted by a career. In the next step, consumers would answer the questions regarding the design features and condition of the products e.g. the memory size of a cellphone. The overall condition of product is being assessed by simply asking a multiple-choice question like 'What condition is your product in?' The set of choices includes broken, good and flawless. The choices are briefly explained to consumers. The buying price is then offered to consumers after they indicate the type of shipping methods: Pre-paid shipping or in-store drop-off. In the case of pre-paid shipping, consumers are usually rewarded less than the case that they return the products in stores. The payment is made to consumers after the reported condition of product is verified by trade-in programs.

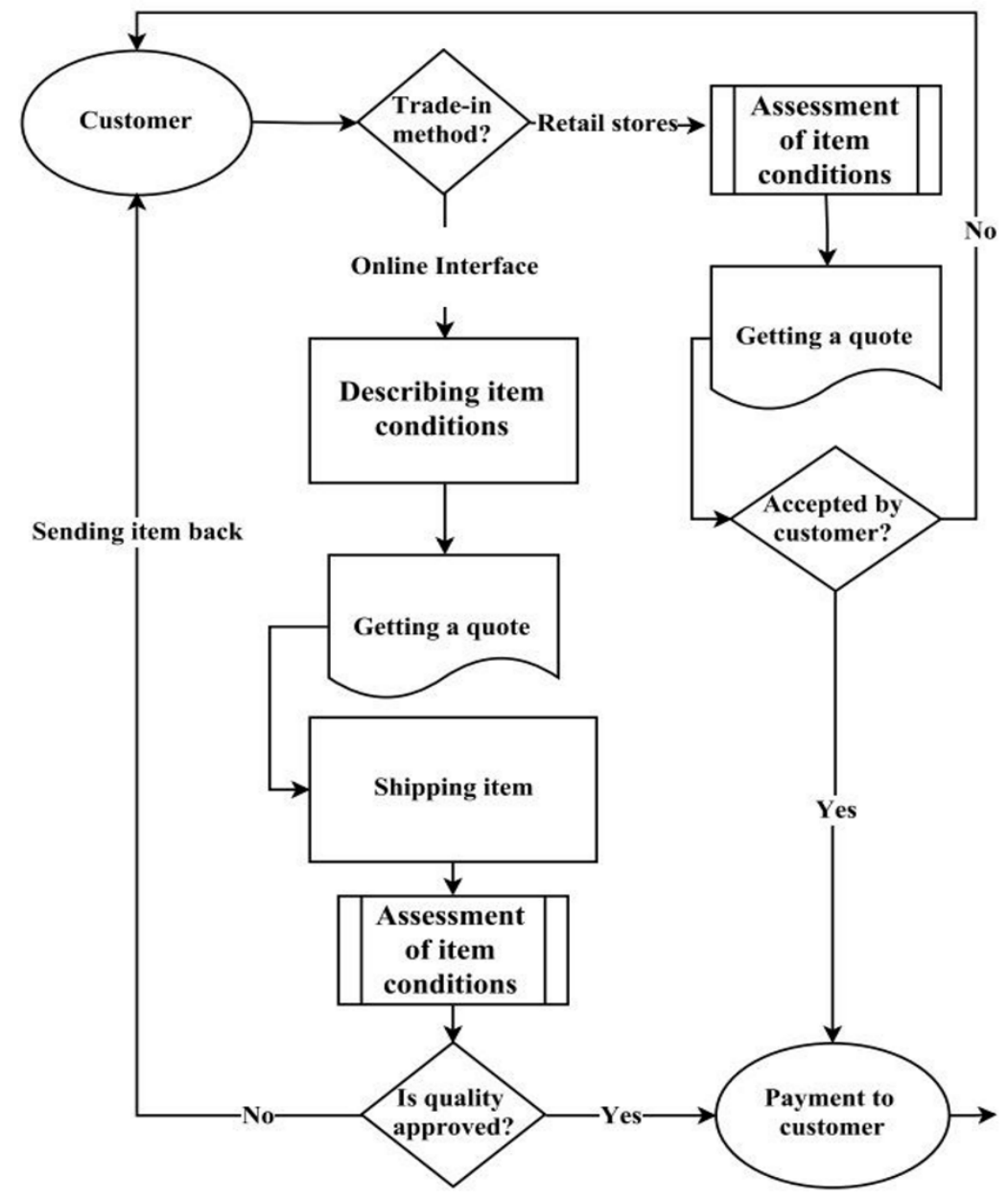

Fig. 1 A typical take-back system flowchart

Therefore, based on the general structure of take-back programs shown in Fig. 1, the gametheoretic model is defined as follows: Consider $N$ consumers who have purchased an electronic device and have used their product for an uncertain amount of time. After usage termination, the consumer 
decides what to do with the unwanted product. Suppose that the original manufacturer offers an incentive to the consumer to not store their used items and return them back for refurbishing or remanufacturing purposes. Consumers' decisions depend on the amount of incentive and their perception of a product's technical and physical obsolescence. Consumers may return the used product immediately after usage termination or keep them in storage. To extract the maximum value embedded in used products and obtain higher profit, OEM prefers to receive products that have been used and stored less. Therefore, the OEM intends to determine the best level of incentive which reduces the storage time and maximizes profit.

To find the equilibrium solution for what both consumers and OEMs require and for taking advantage of established green practices, a game theory decision-making framework is developed. Due to the complexity of the model, two different types of consumers (green and brown) are defined to obtain the closed-form optimal solutions for the game model. The green consumers are likely to be more concerned about environmental impacts of their consumption than the brown consumers [45]. Therefore, under the same conditions, the green consumers tend to store EoU/L products for a shorter period of time than the other group of consumers. In the first part of the model, we investigate this heterogeneity in the storage behavior among consumers. Extension of the model to $N$ heterogeneous types of consumers $(N>2)$ and finding equilibrium solutions might be computationally intractable, since the size of the solution space increases very rapidly [46]. There could be some possibilities for generalizing the model, but they are just limited to changing a single attribute across the consumers [47]. However, in the second part, we extend the model to $N$ types of consumers that behave homogeneously and perceive the same benefits from the take-back program. This section explains the details of the game between the OEM and consumers.

\subsection{Notations}

Table 1 summarizes the notations used to define the model. First, a game model between two different types of consumers and an OEM is discussed, and then it is generalized to a game between $N$ consumers who behave homogenously and an OEM. It is assumed that the consumer has utilized the product for $c$ units of time and the obsolescence status of the used product is evaluated as $\alpha$ at the endof-use phase. The evaluation is based on two points: (i) the higher the product obsolescence rate and usage time, the lower the consumer's desirability to store it [48] and (ii) the existence of endowment effect, in which people attribute more values to what they own when they want to trade it [49]. This evaluation might be adjusted by the information provided by trade-in programs about the product condition.

No matter how low the amount of the incentive is, there are some consumers who just care about the convenience of a take-back program and environmental issues [50] and therefore participate in pro-environmental recycling programs anyway. To address this point, $\varepsilon$ is considered as the advantage of proper recovery treatment and convenience of services reflecting an indirect incentive for consumers. For example, the prepaid shipping option is a feature that newly added to the take-back programs and facilitates consumers' participation. However, we should not expect people to return their used products only because of their environmental concerns [22]. Therefore, a fixed incentive $r$ is offered to consumers for their used products with minimum qualifications. The incentive or buyback price is considered as a fixed number according to the policy of trade-in and take-back programs. Then, the return decision is made by consumers based on their evaluation $(\gamma)$ of the total reward they earn and the product depreciation status. They may decide not to return their product in a short time and store it for potential future reuse and vice versa. 
The maximum possible profit for a refurbished product after payment for return is assumed to be $\rho$. The remanufacturing cost is a major impediment to make profits out of remanufactured products. The cost is directly related to the level of disassembly and repairability of a product and is determined by OEMs in the early design phase [51]. Any increase in the remanufacturability of a product may facilitate remanufacturing operations by the OEM, while enabling other remanufactures to compete with the OEM on the market for recovered products [21]. In addition to the effect of the remanufacturing cost on the profit, the remarketability of a refurbished/remanufactured product is assumed to decrease linearly based on the product age with the constant rate $\xi$. Kwak et al. [52] formulated the second-hand market value of consumer electronics as a function of product age. They fitted different types of functions-including linear and exponential-and reported the associated standard errors that are very close to one another in both cell phone and laptop case studies. Even if we assume an exponential function, it can be substituted by a piecewise linear function. The utility functions of consumer and OEM are quantified based on the above mentioned parameters and variables.

Table 1. Summary of the game theory model notations

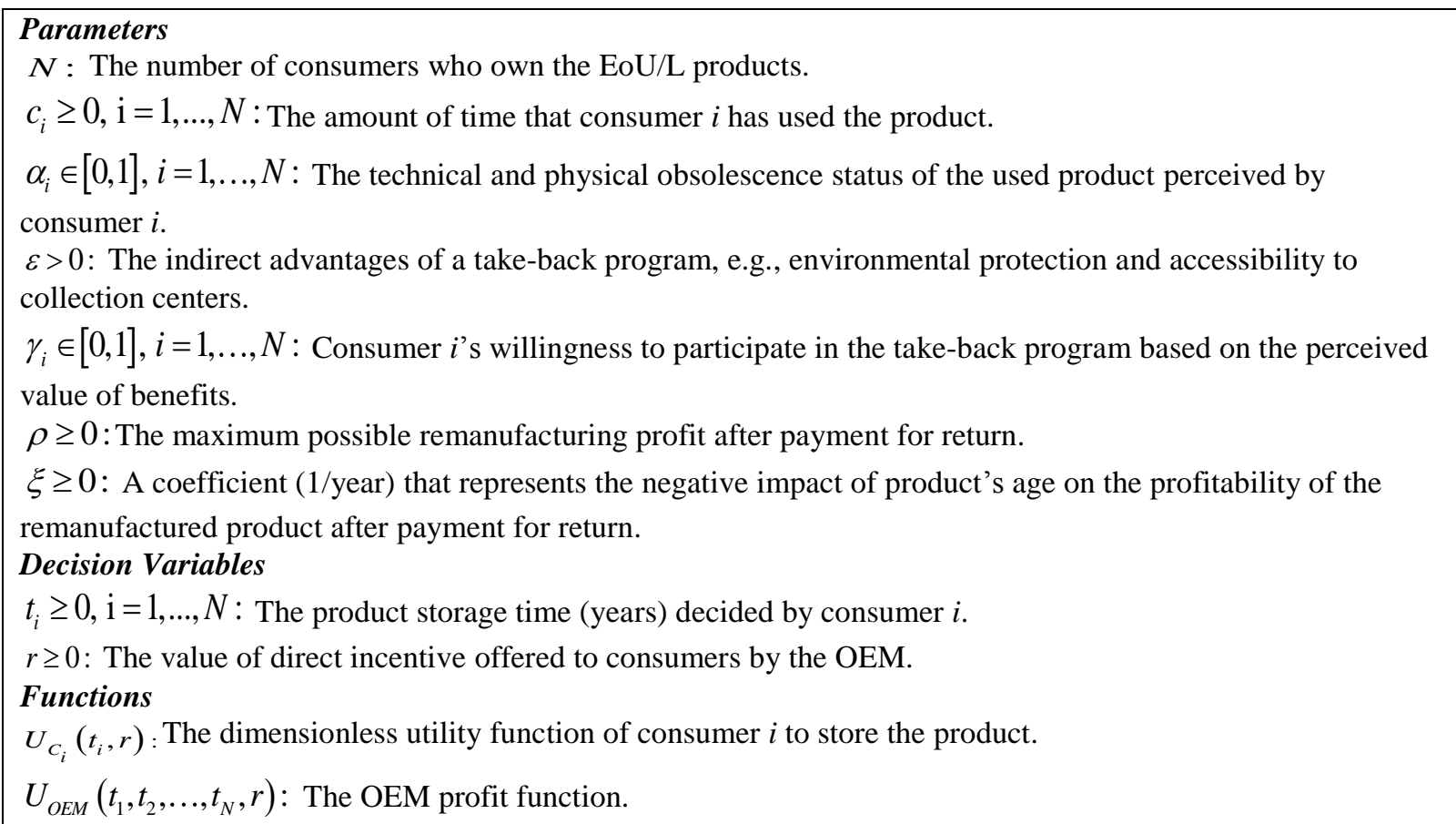

\subsection{Model Assumptions}

It is assumed that there is no inventory limitation and the OEM can remanufacture as many used products as received. This seemingly implausible assumption, however, is justifiable by evidences from market studies and is supported by the remanufacturing community. For example, the total value of the smartphones sold in the US market in 2013 was estimated at $\$ 40$ billion [53], while about $\$ 3.5$ billion of this market was for refurbished and recycled smartphones [54] which is a considerable value. In addition, the trade in remanufactured commodities has been extended to hidden markets in both developed and developing regions [55], where consumers are merely looking for affordable prices. Another assumption is about the quality of the used product. It is assumed that the OEM asks for only a minimum set of qualifications and if the requirements are met, then the consumers are incentivized. In our model, the value of incentive could be set to zero. In this case, a consumer may voluntarily return an item that may have been stored for a long time. The other remanufacturers who 
are certified by the OEM can also remanufacture the used products but with the same mechanism to collect the items.

\subsection{Model Formulation}

Assume that consumer $i$ has used the device for a particular amount of time, $c_{i}$. The incentive $r$ is offered to the consumer to return the item back and the consumer decides whether to stop storing the product or not at time $t_{i}$. The storage desirability function for consumer $i$ is defined as follow:

$$
U_{C_{i}}\left(t_{i}, r\right)=\frac{e^{t_{i}}}{\left(e^{t_{i}+\frac{c_{i}}{\alpha_{i}}}+e^{\frac{1}{\gamma_{i}(r+\varepsilon)}}\right)^{2}}
$$

This shape of utility function has been derived from an empirical study [5]. To justify this utility function, a large data set of 10063 used computers taken back to an e-waste collection site located in Chicago, Illinois, between 2011 and 2013 has been analyzed. The usage time of the returned computers was extracted from the last time the Operation Systems (OS) was used, obtained from their Hard Disk Drives (HDDs), and the manufacturing date. Also, the amount of time that they have been stored by consumers is computed based on the last time the OS was used and the return date. Fig. 2 shows the actual storage and usage times of the mentioned computers for both commercial and household consumers. On average, they had used the products for 5.82 and 5.88 years, respectively. On the other hand, the average amounts of storage time were 1.07 and 1.16 years, respectively. The commercial and household consumers tend to use the products for almost same amount of time ( $p$ value $=0.14)$; however, the household consumers tend to store the products for a longer time than the commercial ones ( $p$-value $=0.00)$. It should be clarified that in the case of this dataset, there is no reward $(r=0)$ for consumers except the environmental, social, and convenient return of e-waste benefits.

Although this dataset is just an example of available take-back programs, it provides some insight about the consumers' attitudes toward returning used products. The storage distributions for both commercial and household consumers are skewed to the left and the modes of distributions are 0.16 and 0.22 years, respectively. Eq. 1 is defined such that it enables us to generate a wide range of storage behavior-including the pro-environmental behavior observed in the current dataset. For those consumers who need financial incentives to return back their used products, offering a higher amount of direct incentive $r$ increases the desirability for a shorter storage time. Likewise, facilitating the participation in take-back programs by increasing the indirect advantages $\varepsilon$ leads to the similar result. Any change in the other parameters of the storage desirability function would result in a particular behavior.
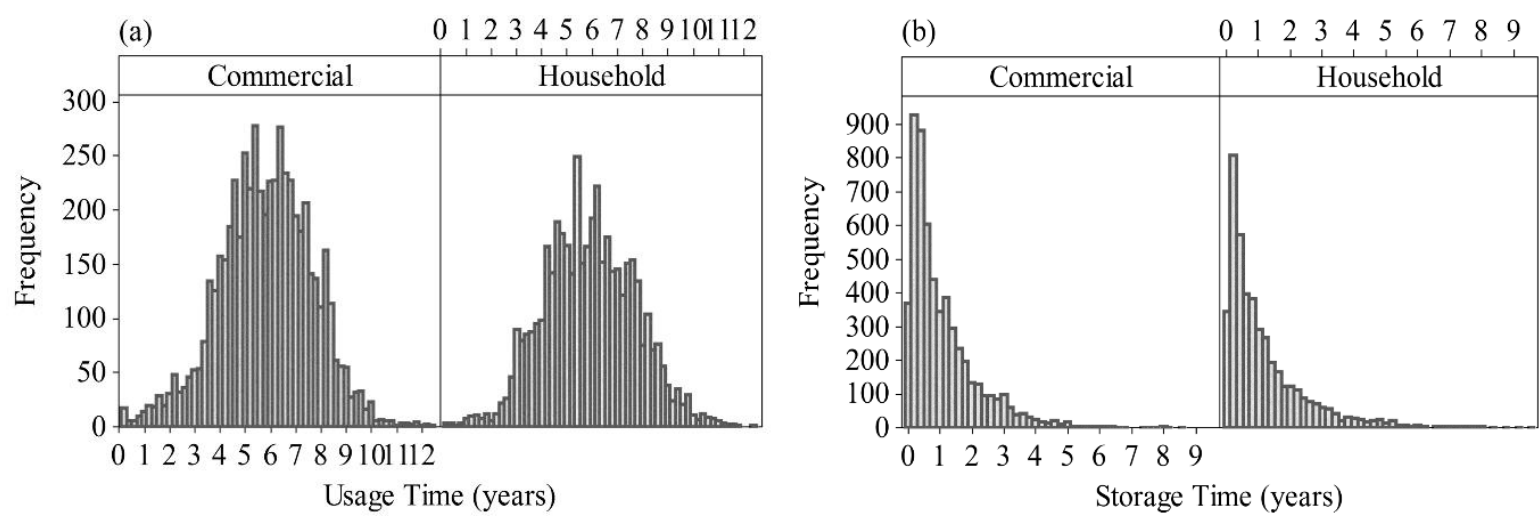
Fig. 2. The distribution of usage time (a) and storage time (b) for the EoU/L computers returned by commercial and household consumers.

The partial derivatives of the consumers' utility function with respect to the parameters and decision variables are as follows:

$$
\begin{aligned}
& \frac{\partial}{\partial t_{i}} U_{C_{i}}=\frac{e^{t_{i}+\frac{1}{\gamma_{i}(r+\varepsilon)}}-e^{2 t_{i}+\frac{c_{i}}{\alpha_{i}}}}{\left(e^{t_{i}+\frac{c_{i}}{\alpha_{i}}}+e^{\frac{1}{\gamma_{i}(r+\varepsilon)}}\right)^{3}}, \begin{cases}\frac{\partial}{\partial t_{i}} U_{C_{i}} \geq 0 \quad \text { if } t_{i} \leq \frac{1}{\gamma_{i}(r+\varepsilon)}-\frac{c_{i}}{\alpha_{i}} \\
\frac{\partial}{\partial t_{i}} U_{C_{i}}<0 \quad \text { if } t_{i}>\frac{1}{\gamma_{i}(r+\varepsilon)}-\frac{c_{i}}{\alpha_{i}}, \lim _{t_{i} \rightarrow \infty} \frac{\partial}{\partial t_{i}} U_{C_{i}}=0,\end{cases} \\
& \frac{\partial}{\partial r} U_{C_{i}}=\frac{2 e^{t_{i}+\frac{1}{\gamma_{i}(r+\varepsilon)}}}{\left(e^{t_{i}+\frac{c_{i}}{\alpha_{i}}}+e^{\frac{1}{\gamma_{i}(r+\varepsilon)}}\right)^{3} \gamma_{i}(r+\varepsilon)^{2}}>0, \frac{\partial}{\partial c_{i}} U_{C_{i}}=-\frac{2 e^{2 t_{i}+\frac{c_{i}}{\alpha_{i}}}}{\left(e^{t_{i}+\frac{c_{i}}{\alpha_{i}}}+e^{\frac{1}{\gamma_{i}(r+\varepsilon)}}\right)^{3} \alpha_{i}}<0 \\
& \frac{\partial}{\partial \alpha_{i}} U_{C_{i}}=\frac{2 c_{i} e^{2 t_{i}+\frac{c_{i}}{\alpha_{i}}}}{\left(e^{t_{i}+\frac{c_{i}}{\alpha_{i}}}+e^{\frac{1}{\gamma_{i}(r+\varepsilon)}}\right)^{3} \alpha_{i}^{2}}>0, \frac{\partial}{\partial \gamma_{i}} U_{C_{i}}=\frac{2 e^{t_{i}+\frac{1}{\gamma_{i}(r+\varepsilon)}}}{\left(e^{t_{i}+\frac{c_{i}}{\alpha_{i}}}+e^{\frac{1}{\gamma_{i}(r+\varepsilon)}}\right)^{3} \gamma_{i}^{2}(r+\varepsilon)}>0, \\
& \frac{\partial}{\partial \varepsilon} U_{C_{i}}=\frac{2 e^{t_{i}+\frac{1}{\gamma_{i}(r+\varepsilon)}}}{\left(e^{t_{i}+\frac{c_{i}}{\alpha_{i}}}+e^{\frac{1}{\gamma_{i}(r+\varepsilon)}}\right)^{3} \gamma_{i}(r+\varepsilon)^{2}}>0
\end{aligned}
$$

According to the partial derivatives, the utility function converges to 0 if consumers store the product for a long time. It means that it is not desired to store the product forever. As shown, any parameters have a positive impact on the consumer utility function except the usage time, $c_{i}$. The consumer would prefer to return a product that has been used for a relatively long time and if it is perceived to be obsolete enough. If an EoU/L product is still in good condition (high values of $\alpha$ ), then the consumer prefers to return it sooner. The high values of $\gamma$ will result in shorter storage time. In other words, the benefits of the take-back program are highly appealing for the consumer. Finally, the direct and indirect incentives may increase the willingness for participation in the take-back programs no matter how the incentives are perceived by the consumers.

To provide a better understanding of the consumers' storage utility function, Fig. 3 (a) illustrates a few samples of the utility functions for different values of $\gamma$. The parameters $c_{i}, \alpha_{i}$, $r$, and $\varepsilon$ are set as $4.5,0.9,25$, and 5 years, respectively. As seen, if a consumer is more willing to participate, then they prefer to return it as soon as possible (comparing the points of time that the consumer's utility function is at its maximum value). Therefore, it is possible to generate different behavior profiles by changing the values of parameters. It should be reemphasized that the storage time $t$ is the time that consumers probably stop storing the products based on their preferences. They may behave differently; meanwhile, e.g., they may discard the products, donate them to charities for reusing, or just give them to their friends or family members.

The utility function (or the profit function) of OEM is defined as the difference between the profit obtained from $N$ refurbished/remanufactured products and the incentive values paid to $N$ consumers as follows:

$$
U_{O E M}\left(t_{1}, t_{2}, \ldots, t_{N}, r\right)=\sum_{i=1}^{N} \rho\left(1-\xi\left(t_{i}+c_{i}\right)\right)-N \times r
$$

The utility function of OEM is defined in such a way that older products bring less profit for the OEM. In other words, it is hard to remarket a technologically obsolete product. Fig. 3 (b) shows the 
utility function of OEM for different values of $\xi$ in the case that there are two different types of consumers. The parameters $\rho, c_{i}, \alpha_{i}, \gamma_{i}$, and $\varepsilon$ are set as 70, 4.5, 0.9, 0.04 and 5 years, respectively. The values of storage time $t$ (the time that consumers stop storing the EoU/L products) are found based on the model results that will be explained in the next part.
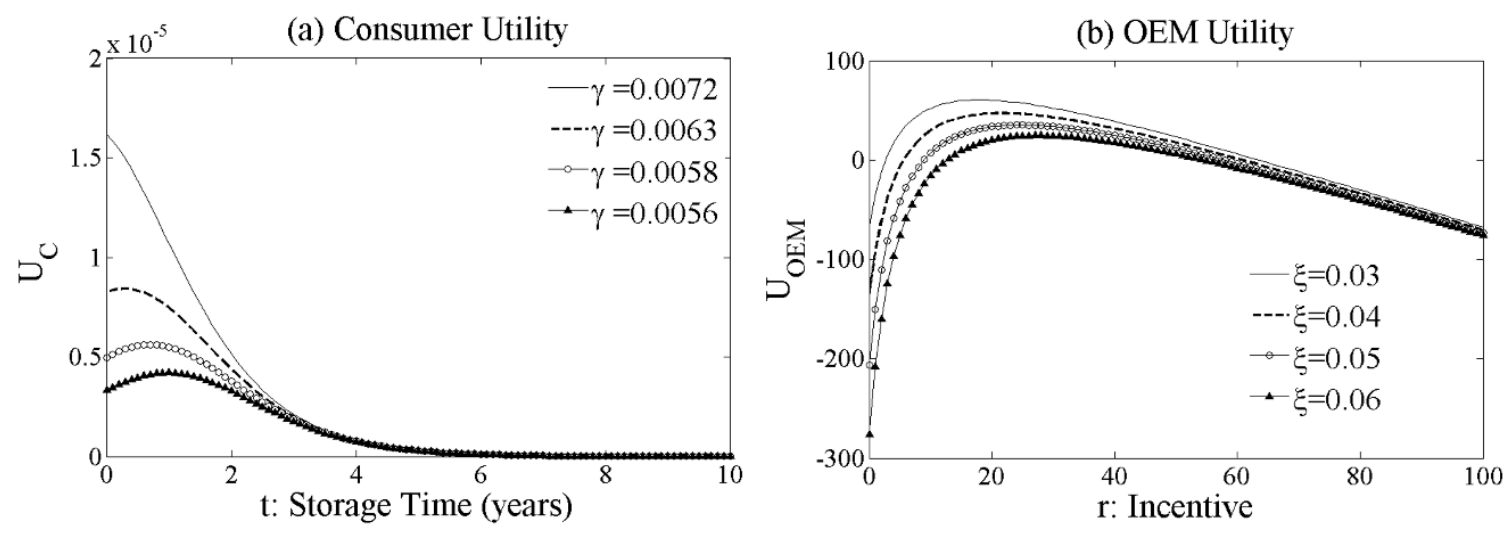

Fig. 3. The consumers' utility functions for different values of $\gamma$. The parameters $c_{i}, \alpha_{i}$, $r$, and $\varepsilon$ are set as $4.5,0.9,25$, and 5 years, respectively (a). The OEM profit functions for different values of $\xi$ in the case that there are two different types of consumers (b). The parameters $\rho, c_{i}, \alpha_{i}, \gamma_{i}$, and $\varepsilon$ are set as 70, 4.5, 0.9, 0.04 and 5 years, respectively.

\subsection{Model Results}

In this section, three theorems are provided to deduce a set of equilibrium strategies for consumers and OEM. A backward induction method is applied to obtain these sub-game perfect Nash equilibrium [56]. Two cases of the game model are examined in which the consumers behave heterogeneously or homogeneously. In the case of two consumers, they can be assumed as the representatives of green and brown consumers. In general, green consumers have more attitudes towards eco-friendly behavior than brown consumers [57]. Next, this case is extended to the case of $N$ homogeneous consumers.

Definition: The vector $\left(t_{1}^{*}, t_{2}^{*}, \ldots, t_{N}^{*}, \mathrm{r}^{*}\right)$ is called a sub-game perfect equilibrium (SPNE) if and only if:

$$
t_{i}^{*}=\hat{t}_{i}\left(\mathrm{r}^{*}\right)=\underset{t_{i}}{\arg \max } U_{C_{i}}\left(t_{i}, r\right), \text { for all } i=1, \ldots, N
$$

and

$$
\mathrm{r}^{*}=\underset{r}{\arg \max } U_{O E M}\left(\hat{t}_{1}(r), \hat{t}_{2}(r), \ldots, \hat{t}_{N}(r), r\right)
$$

Theorem 1 The best response function, the storage time, for consumer $i$ is given by:

$$
\hat{t}_{i}(r)= \begin{cases}\frac{1}{\gamma_{i}(r+\varepsilon)}-\frac{c_{i}}{\alpha_{i}} & \text { if } r<\frac{\alpha_{i}}{\gamma_{i} c_{i}}-\varepsilon \\ 0 & \text { if } r \geq \frac{\alpha_{i}}{\gamma_{i} c_{i}}-\varepsilon\end{cases}
$$

To find the best value of incentive offered by the OEM, the best responses of consumers are put in the OEM's utility function as shown in Eq. 4. For $N=2$, we have: 


$$
\max _{r \geq 0} U_{\text {OEM }}\left(\hat{t}_{1}(r), \hat{t}_{2}(r), r\right)=\left\{\begin{array}{lr}
\rho\left(1-\xi\left(\frac{1}{\gamma_{1}(r+\varepsilon)}+c_{1}\left(1-\frac{1}{\alpha_{1}}\right)\right)\right)+\rho\left(1-\xi\left(\frac{1}{\gamma_{2}(r+\varepsilon)}+c_{2}\left(1-\frac{1}{\alpha_{2}}\right)\right)\right)-2 r \text { if } r<\frac{\alpha_{1}}{\gamma_{1} c_{1}}-\varepsilon \text { and } r<\frac{\alpha_{2}}{\gamma_{2} c_{2}}-\varepsilon \\
\rho\left(1-\xi\left(\frac{1}{\gamma_{1}(r+\varepsilon)}+c_{1}\left(1-\frac{1}{\alpha_{1}}\right)\right)\right)+\rho\left(1-\xi\left(c_{2}\right)\right)-2 r & \text { if } r<\frac{\alpha_{1}}{\gamma_{1} c_{1}}-\varepsilon \text { and } \mathrm{r} \geq \frac{\alpha_{2}}{\gamma_{2} c_{2}}-\varepsilon \\
\rho\left(1-\xi\left(c_{1}\right)\right)+\rho\left(1-\xi\left(\frac{1}{\gamma_{2}(r+\varepsilon)}+c_{2}\left(1-\frac{1}{\alpha_{2}}\right)\right)\right)-2 r & \text { if } r \geq \frac{\alpha_{1}}{\gamma_{1} c_{1}}-\varepsilon \text { and } \mathrm{r}<\frac{\alpha_{2}}{\gamma_{2} c_{2}}-\varepsilon \\
\rho\left(1-\xi\left(c_{1}\right)\right)+\rho\left(1-\xi\left(c_{2}\right)\right)-2 r & \text { if } r \geq \frac{\alpha_{1}}{\gamma_{1} c_{1}}-\varepsilon \text { and } r \geq \frac{\alpha_{2}}{\gamma_{2} c_{2}}-\varepsilon
\end{array}\right.
$$

Theorem 2 For the case of two consumers (or two different types of consumers) $N=2$, the equilibrium $\left(t_{1}^{*}, t_{2}^{*}, \mathrm{r}^{*}\right)$ together with the optimal utility values are listed for nine cases in Table 2 based on different combinations of three decision variables (i.e., the optimal values of storage times and incentive). The feasibility and optimality conditions for each case are put in Table 3.

Remark In reality, there is no case that the optimal values of storage time for both consumers are zero and the OEM offers an incentive to the consumers. Therefore, there are only nine cases of equilibrium although there are ten cases in principal based on the different combinations of three variables.

Now, suppose that there are $N$ consumers who behave homogeneously. It means that all consumers have used the product for the same amount of time $(\bar{c})$, all products are equally obsolete $(\bar{\alpha})$, and finally, the consumers perceive the same benefits $(\bar{\gamma})$ from participation in the take-back program.

$$
\max _{r>0} U_{\text {OEM }}\left(\hat{t}_{1}, \hat{t}_{2}, \ldots, \hat{t}_{N}, r\right)=\left\{\begin{array}{l}
N \rho\left(1-\xi\left(\frac{1}{\bar{\gamma}(r+\varepsilon)}+\bar{c}\left(1-\frac{1}{\bar{\alpha}}\right)\right)\right)-N r \quad \text { if } r \leq \frac{\bar{\alpha}}{\bar{\gamma} \bar{c}}-\varepsilon \\
N \rho(1-\xi \bar{c})-N r \quad \text { if } r>\frac{\bar{\alpha}}{\bar{\gamma} \bar{c}}-\varepsilon
\end{array}\right.
$$

Theorem 3 For the model with $N$ homogeneous consumers, the equilibrium $\left(t_{1}^{*}=t^{*}, t_{2}^{*}=t^{*}, \ldots, t_{N}^{*}=t^{*}, \mathrm{r}^{*}\right)$ together with the optimal utilities, the feasibility and optimality conditions for three cases are shown in Table 4.

Remark In reality, there is no case that the optimal values of the storage time are zero and the OEM considers an incentive for the consumers. That is why there are only three cases of equilibrium although in principal there are four cases based on the different combinations of variables. 
Table 2 Equilibrium solutions for the game between two consumers and the OEM.

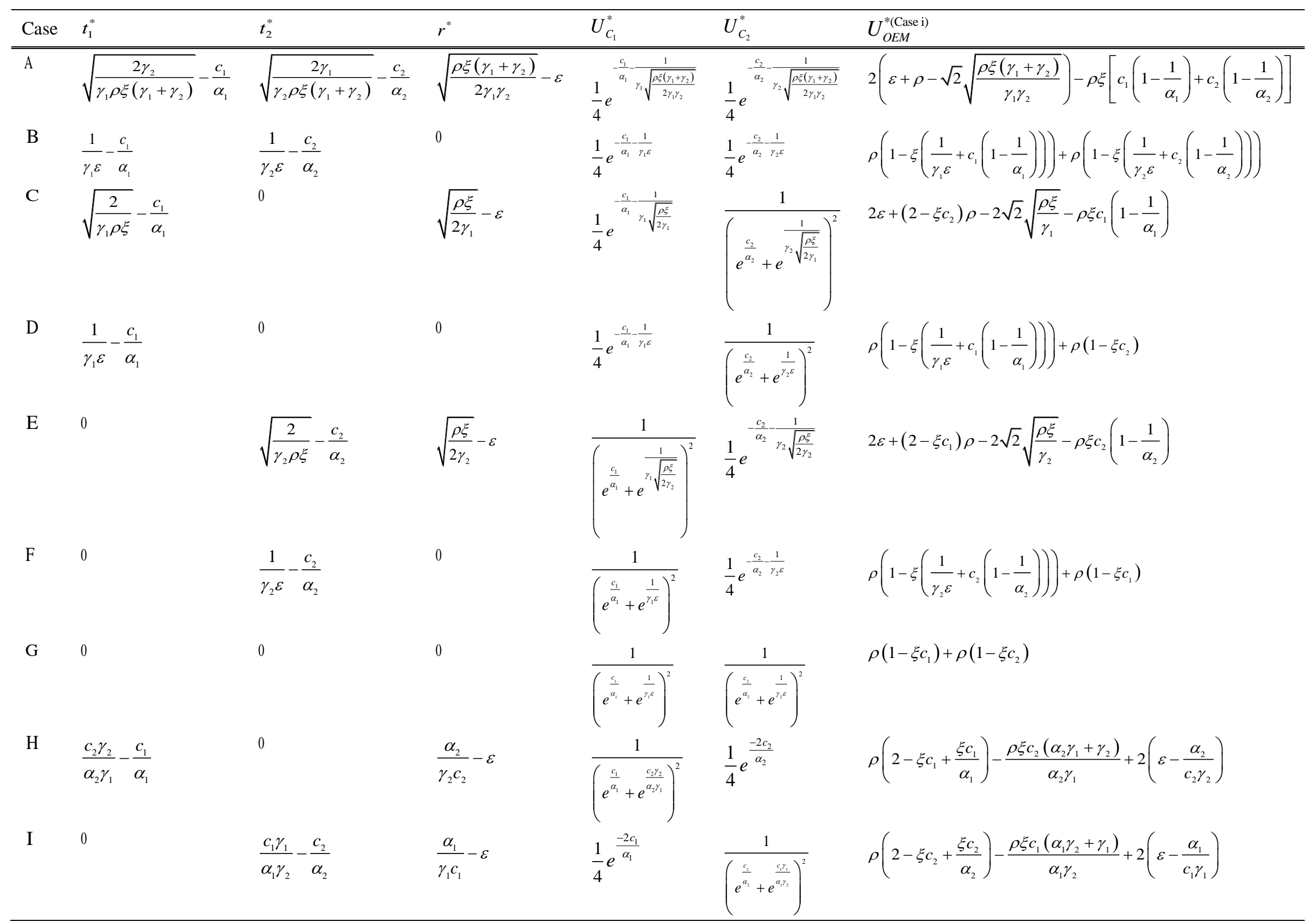


Table 3 Conditions for the equilibrium solutions of a game between two consumers and the OEM

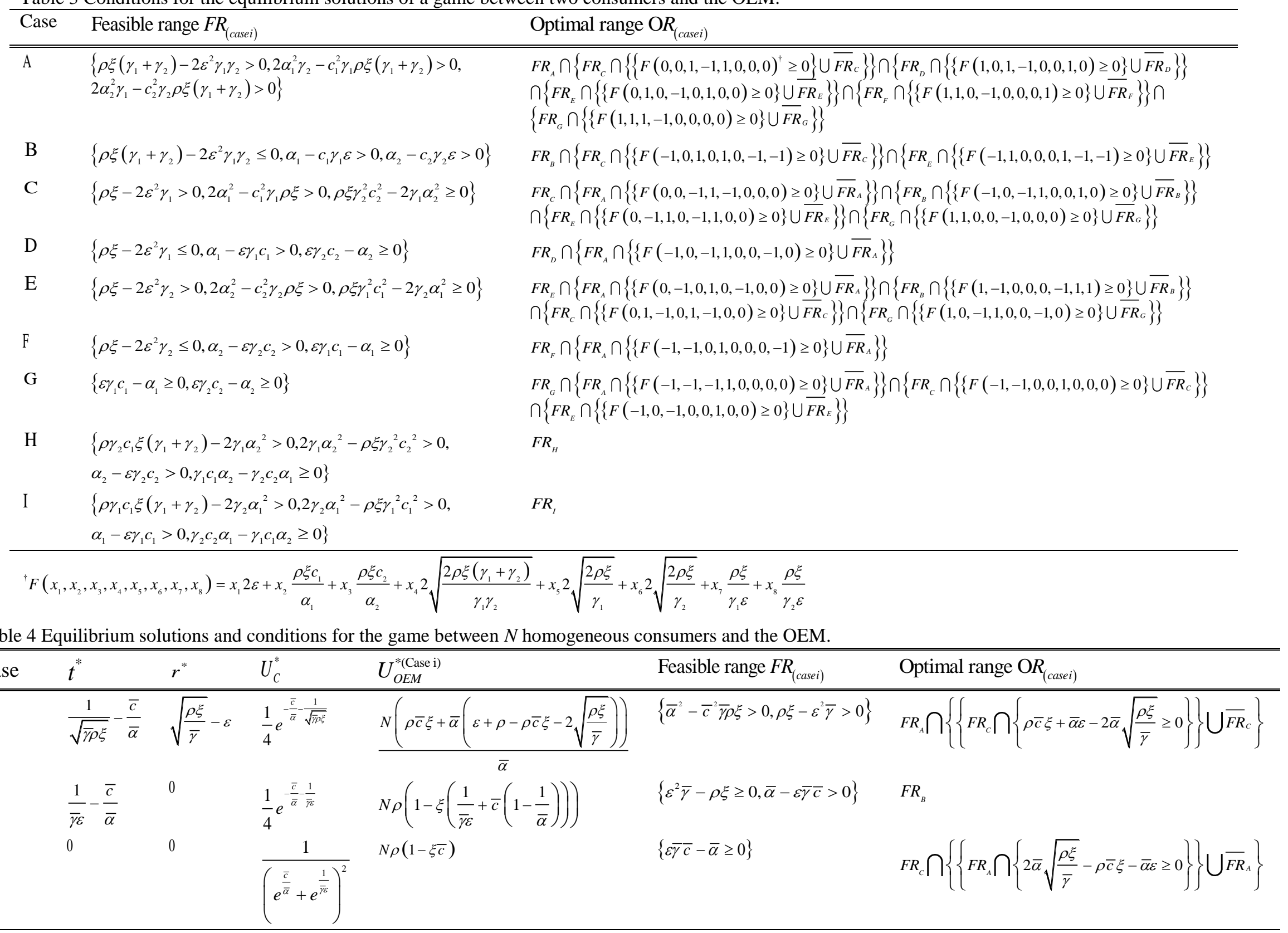




\section{Numerical Example}

A numerical example is provided in this section for a case of laptop. The condition of the laptop is titled as broken (e.g., it does not power on or its display is cracked). One-way sensitivity analyses are considered, where the values of one parameter of the model are varied. Moreover, two-way sensitivity analyses are provided, where two parameters are varied simultaneously.

The lifetime of laptops/computers has been estimated in previous studies. Cox et al. [58] conducted a survey among a group of consumers in the UK and reported that the consensus on the expected computer lifetime was between 3 and 4 years in 2013. In another study [59], the actual average lifetime of discarded computers was 4.9 years that is closer to our dataset. Hence, it seems that the average lifetime of a computer is a wide range of 3-5 years, depending on the socio-economic characteristics of communities. Therefore, according to the information available about the consumer usage behavior, the values of parameters $c_{1}$ and $c_{2}$ are set to 4.5 years, as the baseline.

To capture the negative impact of the age of a product on the profitability of remanufacturing, it is observed that the buy-back price of a laptop decreases by $11 \%$ for every year of age [52]. However, it is assumed that the laptop is used for 4.5 years and is broken. For such described laptops, the depreciation rate in value is possibly less than the one expected for an almost-new and flawless laptop. Thus, 0.03 is taken as the value of $\xi$. The information provided by trade-in programs about the condition of used products may lead consumers to fairly assess the value and obsolescence status of their products. The value of $\alpha$ ranges between 0 and 1. For a laptop with the quality described above, the value of $\alpha$ is likely to be close to zero (completely-obsolete). Based on this logic, the values of parameters $\alpha_{1}$ and $\alpha_{2}$ are set equal to 0.4 , however, these values are selected in a way that represents the ownership effect among different consumers.

In the numerical example, the pre-paid shipping is counted as an indirect advantage. The price of domestic shipping services is estimated to be about $\$ 5$ for a 5-pound laptop [60]. Therefore, $\$ 5$ would be a good estimation for the value of $\varepsilon$. It is not easy to find the maximum possible profit (the selling price minus the remanufacturing cost except the amount of incentive) for a relatively-old and broken laptop that is remanufactured. However, we seek to estimate the net profit by using the selling prices for a specific model of laptop. This model is released to the market in 2016 and priced at $\$ 850$, while the certified refurbished type of this laptop is offered by the original brand for $\$ 600$ at the same time. The net profit margin for the consumer durables is estimated at 6.6\% in 2016 (FactSet Research Systems Inc.). Thus, the maximum possible net profit of the refurbished laptop $(\rho)$ is expected to be nearly \$40. Finally, consumers may have different levels of willingness to participate in such programs based on the perceived benefit which is something subjective. Therefore, 0.005 is chosen as the values of parameters $\gamma_{1}, \gamma_{2}$. It should be noted that the value of parameter $\gamma$ should be scaled based on the magnitude of the monetary value of the incentive to obtain meaningful values for the outputs such as the storage times.

Figs. 4, 5 and 6 illustrate the one-way sensitivity analyses for every single parameter in the case of heterogeneous consumers. To provide a better way to compare with the OEM's utility function, the values of consumers' utility functions are scaled. First, the primary values are mapped to the new values that range from 0 to 1 . Then, the obtained values are multiplied by a constant number (e.g., 50) to get the modified consumer utility function $\left(U_{C}^{* *}\right)$. The optimal amount of incentive $\left(r^{*}\right)$, the optimal values of the storage time $\left(t_{1}^{*}\right.$ and $\left.t_{2}^{*}\right)$, the optimal values of the modified consumers' utility function $\left(U_{C_{1}}^{* *}\right.$ and $\left.U_{C_{2}}^{* *}\right)$, and finally the optimal value of the OEM's utility function $\left(U_{O E M}^{*}\right)$ are plotted. In each sub-graph, the solid vertical line indicates the baseline. 
As seen in Fig. 4 (a-b), the OEM has to offer a larger incentive value if one of the consumers perceives higher value for the stored item. As a result, the second consumer will return the EoU/L items sooner; however, the optimal profit decreases as a result of a larger incentive value. It somehow shows the endowment effect reported in people. If one of the consumers has used the product for a longer period of time, the OEM can offer lower incentive value (Fig. 4 (c-d)). In this case, the profit of OEM increases first and then decreases. The amount of time that the second consumer has used the product is independent from the first consumer. The only value that changes is the value of the incentive. The second consumer will store the product for a longer time if the amount of incentive is very low. That is why the profit of OEM will decrease. Fig. 4 (a) and (b) look similar in appearance as the values for parameters like $\alpha_{1}$ and $\alpha_{2}$ are equally selected for both consumers in the baseline. This similarity is observed in later figures because of the same reason.

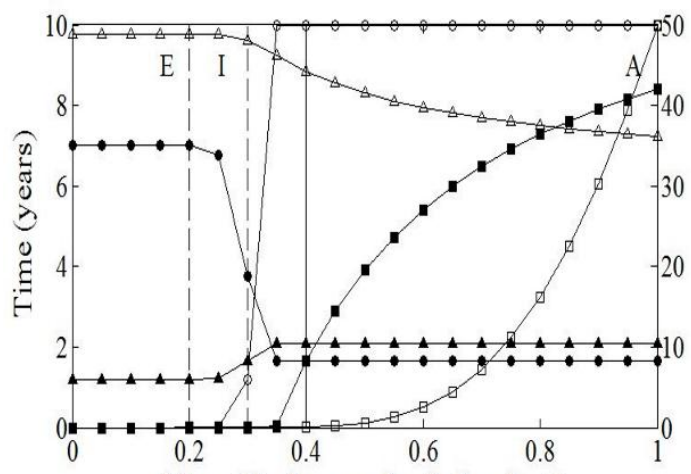

(a) $\alpha_{1}$ : Obsolescence level of product 1

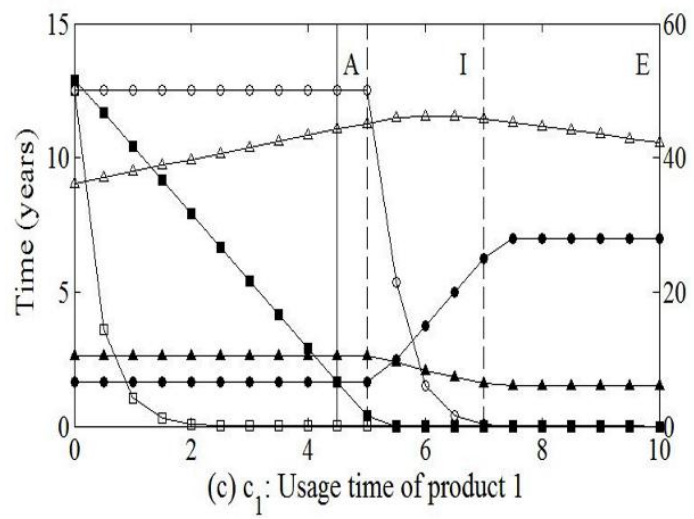

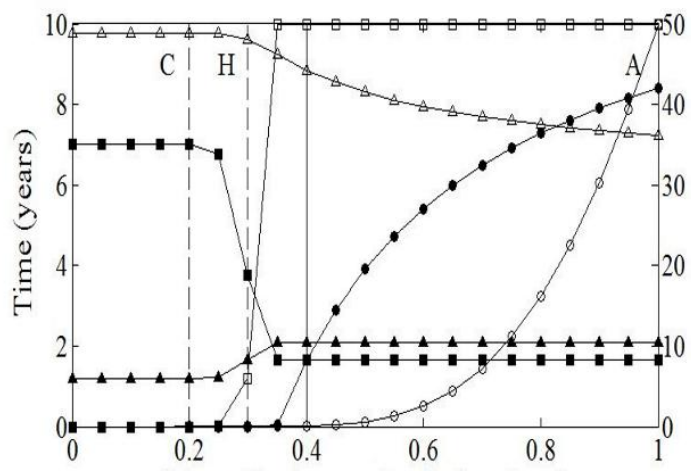

(b) $\alpha_{2}$ : Obsolescence level of product 2

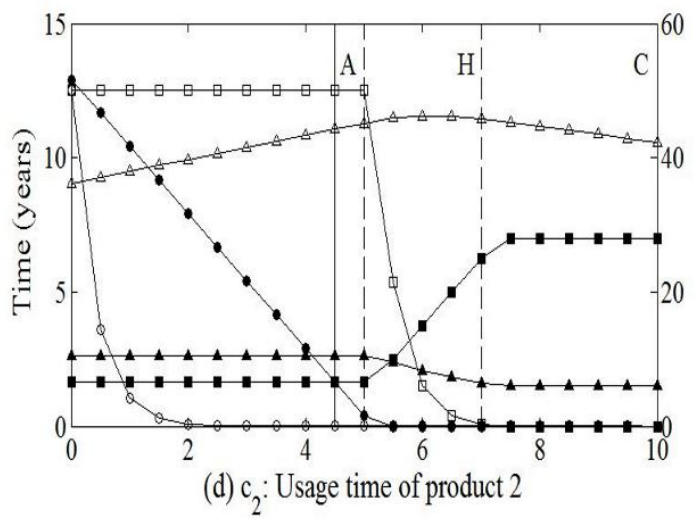

Fig. 4. Transition between the equilibrium cases as parameters $\alpha$ and $c$ change. The values of parameters for the baseline equilibrium are set as $\alpha_{1}=\alpha_{2}=0.4, c_{1}=c_{2}=4.5$ (years), $\gamma_{1}=\gamma_{2}=0.005, \rho=40, \varepsilon=5$, and $\xi=0.03$.

If consumers perceive a higher value of a take-back program's benefits, then they will be highly motivated to participate in the program. Fig. 5 (a-b) shows how the OEM's profit increases in this case. The profit of the remanufacturing activities depends on the market demand. Assuming a constant recovery cost for the used products, if the OEM can sell the refurbished products at a higher price, then a larger incentive value is offered to consumers. As a result, they will return the used products faster (Fig. $5 \mathrm{c}$ ). Although the amount of direct incentive matters to consumers, we believe that indirect incentive is also important for consumers. If consumers are motivated to return a product by indirect incentives such as reducing the environmental impact of a product through recycling combined with the convenience of access to the take-back program, then they will be more inclined to return items sooner. In our model, the consumers perceive the direct and indirect incentive in the same 
way. Therefore, they will ask for a lower amount of direct incentive if they receive a higher value of indirect incentive (Fig. 5 d). Finally, if the profit of remanufacturing activities highly depends on the age of acquired products (a higher $\xi$ ), then the OEM's profit will decrease (Fig. 6).
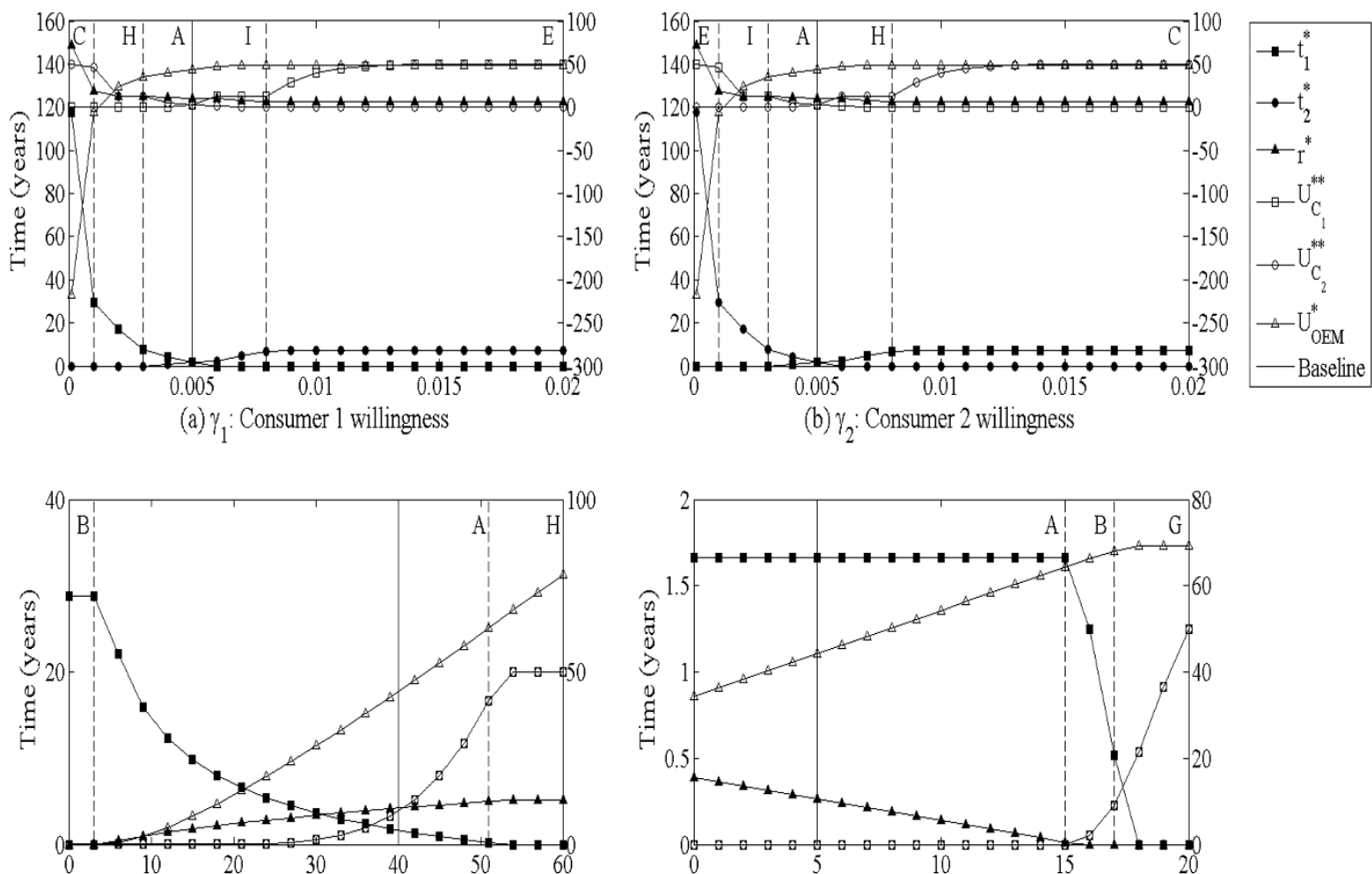

(c) $p$ : Net profit for a remanufactured product

(b) $\gamma_{2}$ : Consumer 2 willingness

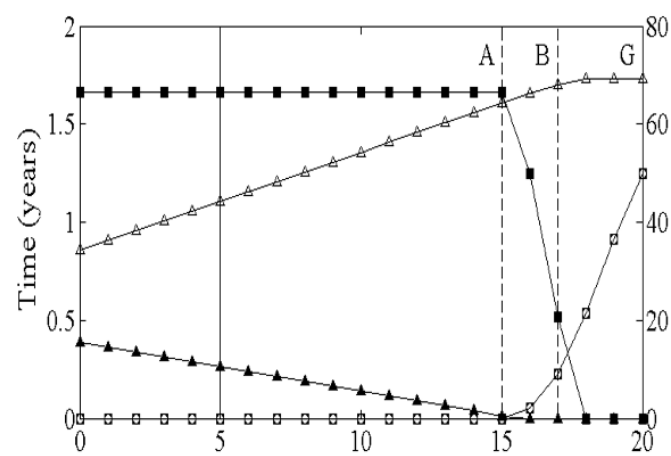

(d) $\varepsilon$ : Indirect advantages of proper recovery

Fig. 5. Transition between the equilibrium cases as parameters $\gamma, \rho$ and $\varepsilon$ change. The values of parameters for the baseline equilibrium are set as $\alpha_{1}=\alpha_{2}=0.4, c_{1}=c_{2}=4.5$ (years), $\gamma_{1}=\gamma_{2}=0.005, \rho=40, \varepsilon=5$, and $\xi=0.03$.

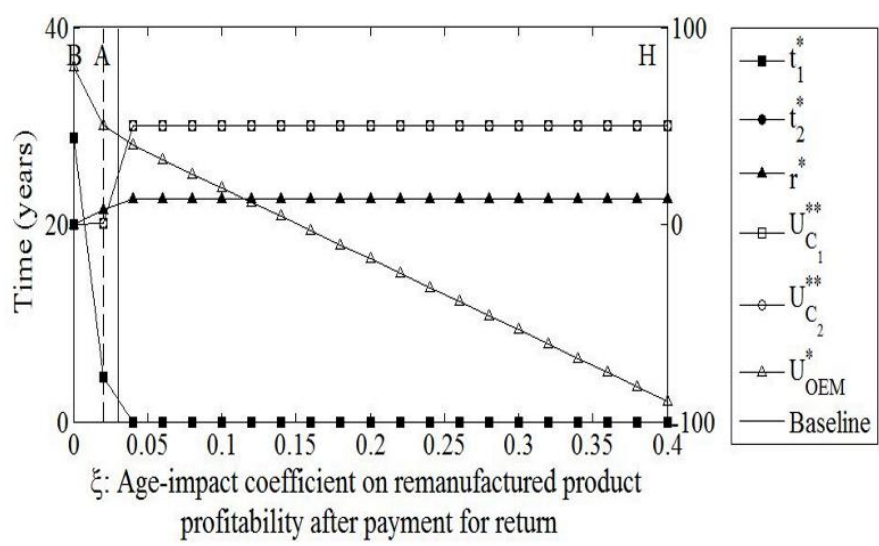

Fig. 6. Transition between the equilibrium cases as parameter $\xi$ changes. The values of parameters for the baseline equilibrium are set as $\alpha_{1}=\alpha_{2}=0.4, c_{1}=c_{2}=4.5$ (years), $\gamma_{1}=\gamma_{2}=$ $0.005, \rho=40, \varepsilon=5$, and $\xi=0.03$.

Fig. 7 also shows the transition between the equilibrium cases when two parameters change at the same time that is more realistic (The asterisk indicates the baseline). For example when the obsolescence levels $\alpha_{1}$ and $\alpha_{2}$ are equal to 0.4, the equilibrium case is $A$. The surface plots in Fig. 8 (ad), represent the optimal values for the storage times, incentive, and the OEM's utility function for the case that $\alpha_{1}$ and $\alpha_{2}$ change simultaneously. For example, when both consumers evaluate the 
obsolescence status of laptops as $0.4, r^{*}$ is $\$ 10.5$ (Fig. 8 c). If they perceive more obsolescence $\left(\alpha_{l}=\right.$ $\left.\alpha_{2}=0.3\right)$, the manufacturer would pay less incentive $\left(r^{*}=\$ 8.3\right)$.

(a)

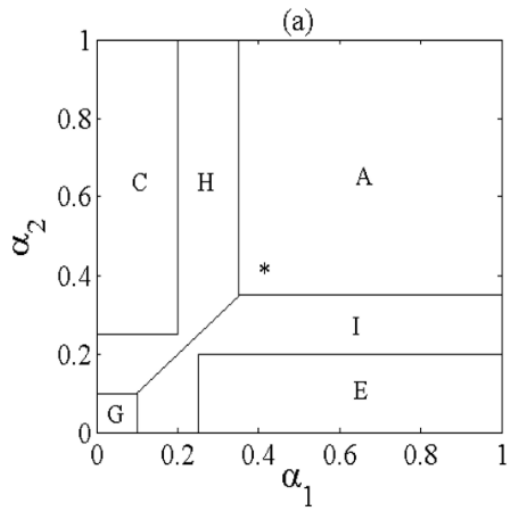

(c)

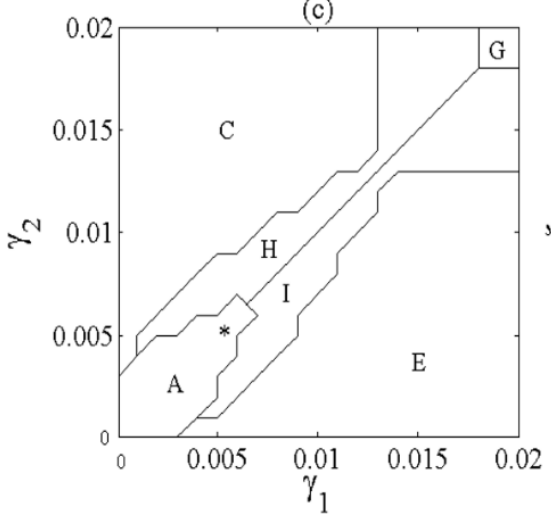

(b)

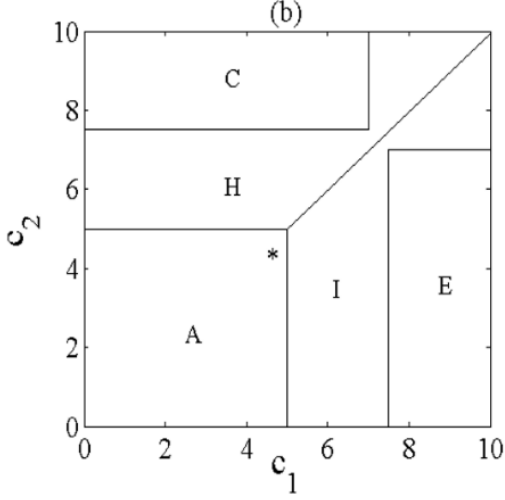

(d)

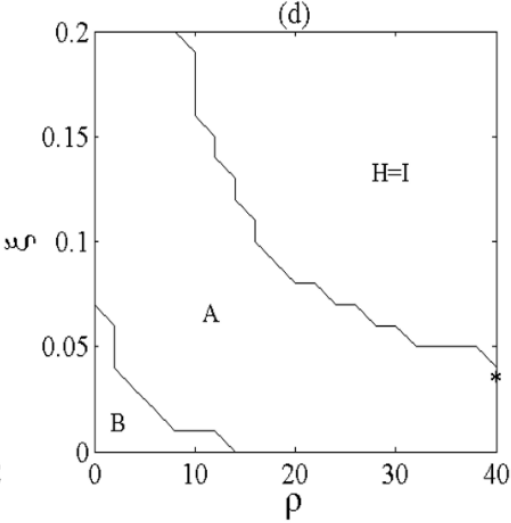

Fig. 7. Transition between the equilibrium cases as two-way function of $\alpha$ (obsolescence level), $c$ (usage time), $\gamma$ (willingness to participate), $\rho$ (profit of a remanufactured product), $\varepsilon$ (indirect incentive), and $\xi$ (Age-impact coefficient). The values of parameters for the baseline equilibrium are set as $\alpha_{1}=\alpha_{2}=0.4, c_{1}=c_{2}=4.5$ (yrs.), $\gamma_{1}=\gamma_{2}=0.005, \rho=40, \varepsilon=5$, and $\xi=0.03$.

(a)

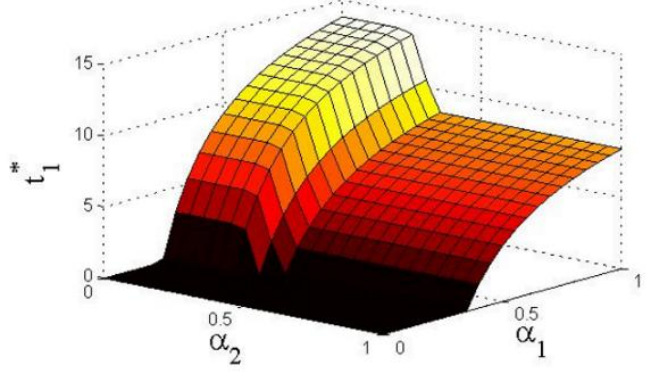

(c)

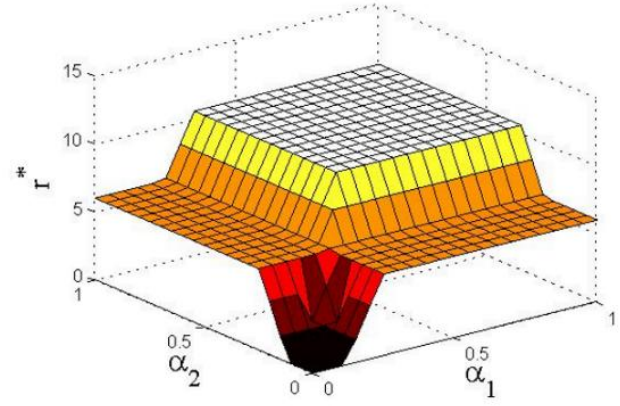

(b)

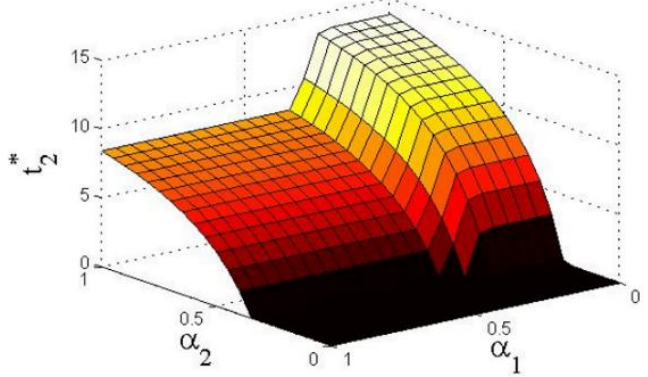

(d)

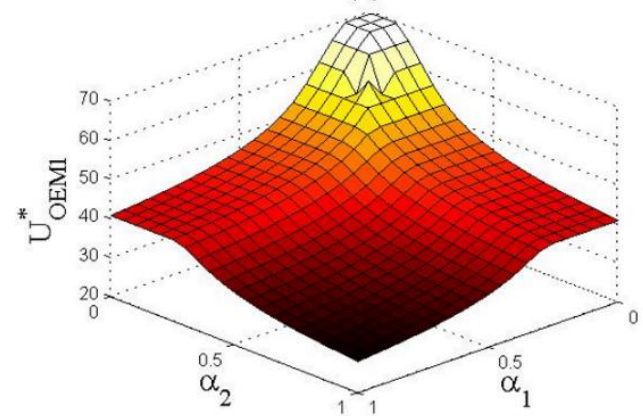


Fig. 8. The optimal values of storage times $t_{1}^{*}$ and $t_{2}^{*}$, incentive $r^{*}$, and the OEM's utility $U_{O E M}^{*}$ as two-way function of obsolescence levels $\alpha_{1}$ and $\alpha_{2}$. The values of parameters for the baseline equilibrium are set as $\alpha_{1}=\alpha_{2}=0.4, c_{I}=c_{2}=4.5$ (yrs.), $\gamma_{1}=\gamma_{2}=$ $0.005, \rho=40, \varepsilon=5$, and $\xi=0.03$.

Using the results of sensitivity analyses, the average age (the summation of usage and storage times) of returns is calculated together with the optimal values of incentive and profit (Table 5). Again, the values of parameters for the baseline equilibrium are set as $\alpha_{1}=\alpha_{2}=0.4, c_{1}=c_{2}=4.5$ (years), $\gamma_{1}=\gamma_{2}=0.005, \rho=40, \varepsilon=5$, and $\xi=0.03$. As stated earlier, the storage time has a negative relationship with the usage time. As an interesting finding, the mean age of returns is at the minimum possible level (mean age $=5.4$ years) when the consumers use products for a moderate amount of time $\left(c_{1}=c_{2}=\right.$ 5 years). Furthermore, if the remanufacturing processes cost less and the remanufactured products are highly demanded in the market $(\rho=50)$, then the average age of returns is at the minimum possible level (age $=4.8$ years) since a higher amount of incentive is offered $\left(r^{*}=12.3\right)$. Finally, the OEM can obtain higher profit if the demand for the furbished products is less age-sensitive (lower value of $\xi$ ).

Table 5 The mean age of returns and optimal values of incentive and profit of remanufacturing operations based on the changes in the model parameters.

\begin{tabular}{|c|c|c|c|c|c|c|c|c|c|c|c|}
\hline \multirow{5}{*}{$\begin{array}{l}\text { Mean Age (years) } \\
\text { Optimal Incentive } \\
\text { Optimal Profit }\end{array}$} & \multicolumn{11}{|c|}{$\alpha_{1}=\alpha_{2}$} \\
\hline & 0 & 0.1 & 0.2 & 0.3 & 0.4 & 0.5 & 0.6 & 0.7 & 0.8 & 0.9 & 1 \\
\hline & 4.5 & 4.5 & 4.5 & 4.5 & 6.2 & 8.4 & 9.9 & 11 & 11.8 & 12.4 & 12.9 \\
\hline & 0 & 0 & 3.9 & 8.3 & 10.5 & 10.5 & 10.5 & 10.5 & 10.5 & 10.5 & 10.5 \\
\hline & 69.2 & 69.2 & 61.4 & 52.5 & 44.2 & 38.8 & 35.2 & 32.7 & 30.7 & 29.2 & 28 \\
\hline & \multicolumn{11}{|c|}{$c_{1}=c_{2}$} \\
\hline & 0 & 1 & 2 & 3 & 4 & 5 & 6 & 7 & 8 & 9 & 10 \\
\hline Mean Age (years) & 12.9 & 11.4 & 9.9 & 8.4 & 6.9 & 5.4 & 6 & 7 & 8 & 9 & 10 \\
\hline Optimal Incentive & 10.5 & 10.5 & 10.5 & 10.5 & 10.5 & 10.5 & 8.3 & 6.4 & 5 & 3.9 & 3 \\
\hline \multirow[t]{3}{*}{ Optimal Profit } & 38 & 31.6 & 35.2 & 38.8 & 42.4 & 46 & 48.9 & 50.3 & 50.8 & 50.6 & 50 \\
\hline & \multicolumn{11}{|c|}{$\gamma_{1}=\gamma_{2}$} \\
\hline & 0.001 & 0.002 & 0.004 & 0.006 & 0.008 & 0.01 & 0.012 & 0.014 & 0.016 & 0.018 & 0.02 \\
\hline Mean Age (years) & 61 & 13.7 & 7.7 & 5 & 4.5 & 4.5 & 4.5 & 4.5 & 4.5 & 4.5 & 4.5 \\
\hline Optimal Incentive & 76.2 & 19.5 & 12.3 & 9.1 & 6.1 & 3.9 & 2.4 & 1.3 & 0.6 & 0 & 0 \\
\hline \multirow[t]{3}{*}{ Optimal Profit } & -219 & 8.2 & 37 & 49.6 & 57 & 61.4 & 64.4 & 66.5 & 68.1 & 69.2 & 69.2 \\
\hline & \multicolumn{11}{|c|}{$\rho$} \\
\hline & 0 & 5 & 10 & 15 & 20 & 25 & 30 & 35 & 40 & 45 & 50 \\
\hline Mean Age (years) & 33.3 & 29.8 & 19.1 & 14.3 & 11.5 & 9.6 & 8.15 & 7.1 & 6.2 & 5.4 & 4.8 \\
\hline Optimal Incentive & 0 & 0.5 & 2.7 & 4.5 & 6 & 7.2 & 8.4 & 9.5 & 10.5 & 11.4 & 12.3 \\
\hline \multirow[t]{3}{*}{ Optimal Profit } & 0 & 0.1 & 3.1 & 8.1 & 14.3 & 21.1 & 28.5 & 36.2 & 44.2 & 52.5 & 61 \\
\hline & \multicolumn{11}{|c|}{$\varepsilon$} \\
\hline & 0 & 2 & 4 & 6 & 8 & 10 & 12 & 14 & 16 & 18 & 20 \\
\hline Mean Age (years) & 6.2 & 6.2 & 6.2 & 6.2 & 6.2 & 6.2 & 6.2 & 6.2 & 5.8 & 4.5 & 4.5 \\
\hline Optimal Incentive & 15.5 & 13.5 & 11.5 & 9.5 & 7.5 & 5.5 & 3.5 & 1.5 & 0 & 0 & 0 \\
\hline \multirow[t]{3}{*}{ Optimal Profit } & 34.2 & 38.2 & 42.2 & 46.2 & 50.2 & 54.2 & 58.2 & 62.2 & 66.2 & 69.2 & 69.2 \\
\hline & \multicolumn{11}{|c|}{$\xi$} \\
\hline & 0 & 0.04 & 0.08 & 0.12 & 0.16 & 0.2 & 0.24 & 0.28 & 0.32 & 0.36 & 0.4 \\
\hline Mean Age (years) & 33.3 & 9.1 & 4.5 & 4.5 & 4.5 & 4.5 & 4.5 & 4.5 & 4.5 & 4.5 & 4.5 \\
\hline Optimal Incentive & 0 & 7.6 & 12.8 & 12.8 & 12.8 & 12.8 & 12.8 & 12.8 & 12.8 & 12.8 & 12.8 \\
\hline Optimal Profit & 80 & 40 & 25.6 & 11.2 & -3.2 & -17.5 & -32 & -46.4 & -60.8 & -75.2 & -89.5 \\
\hline
\end{tabular}

\section{Concluding Remarks}

Despite worldwide efforts aimed to overcome the WEEE problem, WEEE stream management is still a major problem. One of the obstacles to efficiently control the flow of WEEE is the complexity of consumers' behavior. People have a tendency to keep their EoU/L products in storage. This product 
storing behavior is a challenging issue confronting profitability of recovery systems. Offering monetary incentive to consumer is suggested as a potential solution to solve this challenge. This paper aimed to model the game between end users and manufactures/recyclers and provide some insights on the amount of incentive that should be provided to consumers in order to balance storage and product return time.

This paper analyzes the time in which consumers stop storing their used devices given that they make a trade-off between the perceived value of their products and the benefits offered by the original equipment manufacturer to return their products. A game theory model has been developed to represent the interactions between consumers and the original equipment manufacturer. The equilibrium solutions are provided in which homogeneous or non-homogeneous consumers intend to take the items back. Then, a sensitivity analysis is done to give some insights as to how the model actually works in practice. Using the results of this model, the OEM as leader in this game can design some take-back policies to control the rate of returns based on consumers' perceptions of the recovery activities as well as the status of the market. According to the analyses in this study, the derived managerial insights are given as follows:

- The results show that a small increment in the consumers' willingness to participate in the take-back program will bring more profits for the OEM. Free shipping services, guaranteed protection of personal data, and less strict criteria for the acceptance of used products motivate the consumers to return their used items sooner.

- The model suggests that the amount of time that consumers use a product will directly impact the profit of the remanufacturing activities. If the consumers use a product for a relatively short or long period of time, then the expected profit of recovered products will not be at the possible maximum value.

$\circ$ The products should be designed for the ease of recovery process if the manufacturers intend to get profits out of recovery activities. However, the marketing issues like cannibalization [61] would concern the manufacturers to invest in remanufacturable design.

$\circ$ The results of this study can be used in the early phase of product design in the case of mandatory clean production laws. The planned obsolescence policies are detrimental to the profitable remanufacturing activities since the products that quickly become obsolete are not easily remarketable.

This study can be extended in several ways. The proposed strategic decision-making framework should be tested in a real-world setting. Because data on consumer product-storing behavior are just now becoming available [5], further study is warranted. In addition, the parameters of our model are highly sensitive to the type of electronic devices being returned. Hence, this model should be adjusted based on the type of product returned.

Further, the extended post-sale services (e.g., product upgrade plan) should be included in future models to facilitate evaluating the social-economic effects. Furthermore, the case that manufacturers are required to recover a certain portion of the EOU/L items can be investigated in future studies as manufacturers may face some budget and inventory capacity limitations. Therefore, the related constraints can be added to the model.

\section{Acknowledgements}

This material is based upon work supported by the National Science Foundation - USA under grant \#CMMI-1435908. Any opinions, findings, and conclusions or recommendations expressed in this material are those of the authors and do not necessarily reflect the views of the National Science Foundation. 


\section{Appendix}

\section{A.1 Proof of Theorem 1}

The best response of the consumer $i$ is obtained by taking the derivative of the utility function as follows:

$$
\frac{\partial}{\partial t_{i}} U_{C_{i}}=\frac{e^{t_{i}+\frac{1}{\gamma_{i}(r+\varepsilon)}}-e^{2 t_{i}+\frac{c_{i}}{\alpha_{i}}}}{\left(e^{t_{i}+\frac{c_{i}}{\alpha_{i}}}+e^{\frac{1}{\gamma_{i}(r+\varepsilon)}}\right)^{3}}=0 \Rightarrow \hat{t}_{i}(r)=\frac{1}{\gamma_{i}(r+\varepsilon)}-\frac{c_{i}}{\alpha_{i}}
$$

if and only if:

$$
\frac{1}{\gamma_{i}(r+\varepsilon)}-\frac{c_{i}}{\alpha_{i}}>0
$$

and

$$
U_{C_{i}}\left(\frac{1}{\gamma_{i}(r+\varepsilon)}-\frac{c_{i}}{\alpha_{i}}, r\right)=\frac{1}{4 e^{\frac{c_{i}}{\alpha_{i}}+\frac{1}{\gamma_{i}(r+\varepsilon)}}}>U_{C_{i}}(0, r)=\frac{1}{\left(e^{\frac{c_{i}}{\alpha_{i}}}+e^{\frac{1}{\gamma_{i}(r+\varepsilon)}}\right)^{2}}
$$

To check the second necessary condition, we have:

$$
\frac{1}{4 e^{\frac{c_{i}}{\alpha_{i}}+\frac{1}{\gamma_{i}(r+\varepsilon)}}}>\frac{1}{\left(e^{\frac{c_{i}}{\alpha_{i}}}+e^{\frac{1}{\gamma_{i}(r+\varepsilon)}}\right)^{2}} \Rightarrow\left(e^{\frac{c_{i}}{\alpha_{i}}}+e^{\frac{1}{\gamma_{i}(r+\varepsilon)}}\right)^{2}-4 e^{\frac{c_{i}}{\alpha_{i}}+\frac{1}{\gamma_{i}(r+\varepsilon)}}>0 \Rightarrow\left(e^{\frac{c_{i}}{\alpha_{i}}}-e^{\frac{1}{\gamma_{i}(r+\varepsilon)}}\right)^{2}>0
$$

So, we can conclude that the non-negativity of $\frac{1}{\gamma_{i}(r+\varepsilon)}-\frac{c_{i}}{\alpha_{i}}$ guarantees the existence of a positive value for the best response of consumer $i$. If $t_{i}$ goes to infinity (i.e., the used product is stored for a long time), then the consumer utility function converges to zero. Then, the best value for the storage time is zero if $\frac{1}{\gamma_{i}(r+\varepsilon)}-\frac{c_{i}}{\alpha_{i}}$ is a negative value and the consumer prefers to take back the used product immediately after the last time of usage.

\section{A.2 Proof of Theorem 2}

\section{A.2.1 Proof of Equilibrium Solutions: the Case of Two Consumers}

As discussed in Sec. 3, nine equilibrium cases are derived. For each case, the optimal utility function of OEM and the related set of feasibility conditions are represented by $U_{O E M}^{* \text { (Case } i)}$ and $F R_{(\text {Cassi })}$ for $\forall i=A, \ldots, I$. (i) When $t_{1}^{*}>0, t_{2}^{*}>0$ : according to the results of Theorem 1, we have $t_{1}^{*}=\frac{1}{\gamma_{1}\left(r^{*}+\varepsilon\right)}-\frac{c_{1}}{\alpha_{1}}$ and $t_{2}^{*}=\frac{1}{\gamma_{2}\left(r^{*}+\varepsilon\right)}-\frac{c_{2}}{\alpha_{2}}$. Then, the utility function of OEM can be obtained as:

$$
U_{O E M}\left(r^{*}\right)=\rho\left(1-\xi\left(\frac{1}{\gamma_{1}\left(r^{*}+\varepsilon\right)}+c_{1}\left(1-\frac{1}{\alpha_{1}}\right)\right)\right)+\rho\left(1-\xi\left(\frac{1}{\gamma_{2}\left(r^{*}+\varepsilon\right)}+c_{2}\left(1-\frac{1}{\alpha_{2}}\right)\right)\right)-2 r^{*}
$$

The best value for the incentive that maximizes the utility function is derived as: 


$$
r^{*}= \begin{cases}\sqrt{\frac{\rho \xi\left(\gamma_{1}+\gamma_{2}\right)}{2 \gamma_{1} \gamma_{2}}}-\varepsilon & \text { if } \sqrt{\frac{\rho \xi\left(\gamma_{1}+\gamma_{2}\right)}{2 \gamma_{1} \gamma_{2}}}>\varepsilon \\ 0 & \text { if } \sqrt{\frac{\rho \xi\left(\gamma_{1}+\gamma_{2}\right)}{2 \gamma_{1} \gamma_{2}}} \leq \varepsilon\end{cases}
$$

Case A: when $r^{*}>0$, the optimal values for the set of decision variables and utility functions are obtained as:

$$
\begin{aligned}
& t_{1}^{*}=\sqrt{\frac{2 \gamma_{2}}{\gamma_{1} \rho \xi\left(\gamma_{1}+\gamma_{2}\right)}}-\frac{c_{1}}{\alpha_{1}}, t_{2}^{*}=\sqrt{\frac{2 \gamma_{1}}{\gamma_{2} \rho \xi\left(\gamma_{1}+\gamma_{2}\right)}}-\frac{c_{2}}{\alpha_{2}}, r^{*}=\sqrt{\frac{\rho \xi\left(\gamma_{1}+\gamma_{2}\right)}{2 \gamma_{1} \gamma_{2}}}-\varepsilon \\
& U_{C_{1}}^{*}=\frac{1}{4} e^{-\frac{c_{1}}{\alpha_{1}}-\frac{1}{\gamma_{1} \sqrt{\frac{\rho \xi\left(\gamma_{1}+\gamma_{2}\right)}{2 \gamma_{1} \gamma_{2}}}}}, U_{C_{2}}^{*}=\frac{1}{4} e^{-\frac{c_{2}}{\alpha_{2}}-\frac{1}{\gamma_{2} \sqrt{\frac{\rho \xi\left(\gamma_{1}+\gamma_{2}\right)}{2 \gamma_{1} \gamma_{2}}}}} \\
& U_{O E M}^{*(\mathrm{~A})}=2\left(\varepsilon+\rho-\sqrt{2} \sqrt{\frac{\rho \xi\left(\gamma_{1}+\gamma_{2}\right)}{\gamma_{1} \gamma_{2}}}\right)-\rho \xi\left[c_{1}\left(1-\frac{1}{\alpha_{1}}\right)+c_{2}\left(1-\frac{1}{\alpha_{2}}\right)\right]
\end{aligned}
$$

The feasible set for this case is $F R_{A}=\left\{\rho \xi\left(\gamma_{1}+\gamma_{2}\right)-2 \varepsilon^{2} \gamma_{1} \gamma_{2}>0,2 \alpha_{1}^{2} \gamma_{2}-c_{1}^{2} \gamma_{1} \rho \xi\left(\gamma_{1}+\gamma_{2}\right)>0,2 \alpha_{2}^{2} \gamma_{1}\right.$ $\left.-c_{2}^{2} \gamma_{2} \rho \xi\left(\gamma_{1}+\gamma_{2}\right)>0\right\}$.

Case B: when $r^{*}=0$, the optimal values can be obtained as:

$$
\begin{gathered}
t_{1}^{*}=\frac{1}{\gamma_{1} \varepsilon}-\frac{c_{1}}{\alpha_{1}}, t_{2}^{*}=\frac{1}{\gamma_{2} \varepsilon}-\frac{c_{2}}{\alpha_{2}}, r^{*}=0 \\
U_{C_{1}}^{*}=\frac{1}{4} e^{-\frac{c_{1}}{\alpha_{1}}-\frac{1}{\gamma_{1} \varepsilon}}, U_{C_{2}}^{*}=\frac{1}{4} e^{-\frac{c_{2}}{\alpha_{2}}-\frac{1}{\gamma_{2} \varepsilon}} \\
U_{O E M}^{*(\mathrm{~B})}=\rho\left(1-\xi\left(\frac{1}{\gamma_{1} \varepsilon}+c_{1}\left(1-\frac{1}{\alpha_{1}}\right)\right)\right)+\rho\left(1-\xi\left(\frac{1}{\gamma_{2} \varepsilon}+c_{2}\left(1-\frac{1}{\alpha_{2}}\right)\right)\right)
\end{gathered}
$$

The feasible range for this case is $F R_{B}=\left\{\rho \xi\left(\gamma_{1}+\gamma_{2}\right)-2 \varepsilon^{2} \gamma_{1} \gamma_{2} \leq 0, \alpha_{1}-c_{1} \gamma_{1} \varepsilon>0, \alpha_{2}-c_{2} \gamma_{2} \varepsilon>0\right\}$.

(ii) When $t_{1}^{*}>0, t_{2}^{*}=0$, the optimal value for $t_{1}^{*}$ is $\frac{1}{\gamma_{1}\left(r^{*}+\varepsilon\right)}-\frac{c_{1}}{\alpha_{1}}$. Then, the utility function of the OEM is modified as:

$$
U_{O E M}\left(r^{*}\right)=\rho\left(1-\xi\left(\frac{1}{\gamma_{1}\left(r^{*}+\varepsilon\right)}+c_{1}\left(1-\frac{1}{\alpha_{1}}\right)\right)\right)+\rho\left(1-\xi\left(\frac{c_{2}}{\alpha_{2}}\right)\right)-2 r^{*}
$$

Similarly, we can find the best value for the incentive as:

$$
r^{*}= \begin{cases}\sqrt{\frac{\rho \xi}{2 \gamma_{1}}}-\varepsilon & \text { if } \sqrt{\frac{\rho \xi}{2 \gamma_{1}}}>\varepsilon \\ 0 & \text { if } \sqrt{\frac{\rho \xi}{2 \gamma_{1}}} \leq \varepsilon\end{cases}
$$

Case $C$ : when $r^{*}>0$, the optimal values are:

$$
t_{1}^{*}=\sqrt{\frac{2}{\gamma_{1} \rho \xi}}-\frac{c_{1}}{\alpha_{1}}, t_{2}^{*}=0, r^{*}=\sqrt{\frac{\rho \xi}{2 \gamma_{1}}}-\varepsilon
$$




$$
\begin{gathered}
U_{C_{1}}^{*}=\frac{1}{4} e^{-\frac{c_{1}}{\alpha_{1}}-\frac{1}{\gamma_{1} \sqrt[\rho \xi]{\frac{\rho \xi}{2 \gamma_{1}}}}}, U_{C_{2}}^{*}=\frac{1}{\left(e^{\frac{c_{2}}{\alpha_{2}}}+e^{\left.\frac{1}{\gamma_{2} \sqrt{\frac{\rho \xi}{2 \gamma_{1}}}}\right)^{2}}\right.} \\
U_{O E M}^{*(\mathrm{C})}=2 \varepsilon+\left(2-\xi c_{2}\right) \rho-2 \sqrt{2} \sqrt{\frac{\rho \xi}{\gamma_{1}}}-\rho \xi c_{1}\left(1-\frac{1}{\alpha_{1}}\right)
\end{gathered}
$$

And the feasible range is obtained as $F R_{C}=\left\{\rho \xi-2 \varepsilon^{2} \gamma_{1}>0,2 \alpha_{1}^{2}-c_{1}^{2} \gamma_{1} \rho \xi>0, \rho \xi \gamma_{2}^{2} c_{2}^{2}-2 \gamma_{1} \alpha_{2}^{2} \geq 0\right\}$.

Case D: when $r^{*}=0$, we obtain the optimal values as:

$$
\begin{gathered}
t_{1}^{*}=\frac{1}{\gamma_{1} \varepsilon}-\frac{c_{1}}{\alpha_{1}}, t_{2}^{*}=0, r^{*}=0 \\
U_{C_{1}}^{*}=\frac{1}{4} e^{-\frac{c_{1}}{\alpha_{1}}-\frac{1}{\gamma_{1} \varepsilon}}, U_{C_{2}}^{*}=\frac{1}{\left(e^{\frac{c_{2}}{\alpha_{2}}}+e^{\frac{1}{\gamma_{2} \varepsilon}}\right)^{2}} \\
U_{O E M}^{*(\mathrm{D})}=\rho\left(1-\xi\left(\frac{1}{\gamma_{1} \varepsilon}+c_{1}\left(1-\frac{1}{\alpha_{1}}\right)\right)\right)+\rho\left(1-\xi c_{2}\right)
\end{gathered}
$$

The feasible range is obtained as $F R_{D}=\left\{\rho \xi-2 \varepsilon^{2} \gamma_{1} \leq 0, \alpha_{1}-\varepsilon \gamma_{1} c_{1}>0, \varepsilon \gamma_{2} c_{2}-\alpha_{2} \geq 0\right\}$.

(iii) When $t_{1}^{*}=0, t_{2}^{*}>0$, the value of $t_{2}^{*}$ is $\frac{1}{\gamma_{2}\left(r^{*}+\varepsilon\right)}-\frac{c_{2}}{\alpha_{2}}$. Then, the utility function of the OEM is as:

$$
U_{\text {OЕM }}\left(r^{*}\right)=\rho\left(1-\xi c_{1}\right)+\rho\left(1-\xi\left(\frac{1}{\gamma_{2}\left(r^{*}+\varepsilon\right)}+c_{2}\left(1-\frac{1}{\alpha_{2}}\right)\right)\right)-2 r^{*}
$$

And according to Theorem 1, the optimal value of the incentive is found as:

$$
r^{*}= \begin{cases}\sqrt{\frac{\rho \xi}{2 \gamma_{2}}}-\varepsilon & \text { if } \sqrt{\frac{\rho \xi}{2 \gamma_{2}}}>\varepsilon \\ 0 & \text { if } \sqrt{\frac{\rho \xi}{2 \gamma_{2}}} \leq \varepsilon\end{cases}
$$

Case E: When $r^{*}>0$, the optimal values of the variables and utility functions per equations are:

$$
\begin{gathered}
t_{1}^{*}=0, t_{2}^{*}=\sqrt{\frac{2}{\gamma_{2} \rho \xi}}-\frac{c_{2}}{\alpha_{2}}, r^{*}=\sqrt{\frac{\rho \xi}{2 \gamma_{2}}}-\varepsilon \\
U_{C_{1}}^{*}=\frac{1}{\left(e^{\frac{c_{1}}{\alpha_{1}}}+e^{\left.\frac{1}{\gamma_{1} \sqrt{\frac{\rho \xi}{2 \gamma_{2}}}}\right)^{2}}, U_{C_{2}}^{*}=\frac{1}{4} e^{-\frac{c_{2}}{\alpha_{2}}-\frac{1}{\gamma_{2} \sqrt{\frac{\rho \xi}{2 \gamma_{2}}}}}\right.} \\
U_{O E M}^{*(\mathrm{E})}=2 \varepsilon+\left(2-\xi c_{1}\right) \rho-2 \sqrt{2} \sqrt{\frac{\rho \xi}{\gamma_{2}}}-\rho \xi c_{2}\left(1-\frac{1}{\alpha_{2}}\right)
\end{gathered}
$$

The feasible range $F R_{E}$ is $\left\{\rho \xi-2 \varepsilon^{2} \gamma_{2}>0,2 \alpha_{2}^{2}-c_{2}^{2} \gamma_{2} \rho \xi>0, \rho \xi \gamma_{1}^{2} c_{1}^{2}-2 \gamma_{2} \alpha_{1}^{2} \geq 0\right\}$.

Case F: When $r^{*}=0$, the optimal values of the variables and utility functions are: 


$$
\begin{gathered}
t_{1}^{*}=0, t_{2}^{*}=\frac{1}{\gamma_{2} \varepsilon}-\frac{c_{2}}{\alpha_{2}}, r^{*}=0 \\
U_{C_{1}}^{*}=\frac{1}{\left(e^{\frac{c_{1}}{\alpha_{1}}}+e^{\frac{1}{\gamma_{1} \varepsilon}}\right)^{2}}, U_{C_{2}}^{*}=\frac{1}{4} e^{-\frac{c_{2}}{\alpha_{2}}-\frac{1}{\gamma_{2} \varepsilon}} \\
U_{O E M}^{* * \mathrm{~F}}=\rho\left(1-\xi\left(\frac{1}{\gamma_{2} \varepsilon}+c_{2}\left(1-\frac{1}{\alpha_{2}}\right)\right)\right)+\rho\left(1-\xi c_{1}\right)
\end{gathered}
$$

And its feasible range is $F R_{F}=\left\{\rho \xi-2 \varepsilon^{2} \gamma_{2} \leq 0, \alpha_{2}-\varepsilon \gamma_{2} c_{2}>0, \varepsilon \gamma_{1} c_{1}-\alpha_{1} \geq 0\right\}$.

(iv) When $t_{1}^{*}=0, t_{2}^{*}=0$, the utility function of the OEM is $U_{\text {OEM }}\left(r^{*}\right)=\rho\left(1-\xi\left(c_{1}\right)\right)+\rho\left(1-\xi\left(c_{2}\right)\right)-2 r^{*}$.

Looking at the function, it is maximized when the incentive value is set to zero. Thus, there should be only one case of equilibrium.

$\underline{\text { Case } G}$ : When $t_{1}^{*}=0, t_{2}^{*}=0$, the optimal values of the utility functions are:

$$
\begin{gathered}
t_{1}^{*}=0, t_{2}^{*}=0, r^{*}=0 \\
U_{C_{1}}^{*}=\frac{1}{\left(e^{\frac{c_{1}}{\alpha_{1}}}+e^{\frac{1}{\gamma_{1} \varepsilon}}\right)^{2}}, U_{C_{2}}^{*}=\frac{1}{\left(e^{\frac{c_{2}}{\alpha_{2}}}+e^{\frac{1}{\gamma_{2}}}\right)^{2}} \\
U_{O E M}^{*(G)}=\rho\left(1-\xi\left(c_{1}\right)\right)+\rho\left(1-\xi\left(c_{2}\right)\right)
\end{gathered}
$$

The feasible range for this case is $F R_{G}=\left\{\varepsilon \gamma_{1} c_{1}-\alpha_{1} \geq 0, \varepsilon \gamma_{2} c_{2}-\alpha_{2} \geq 0\right\}$.

Case H: When $r_{\text {Case A }}^{*}>\min \left\{\frac{\alpha_{1}}{\gamma_{1} c_{1}}-\varepsilon, \frac{\alpha_{2}}{\gamma_{2} c_{2}}-\varepsilon\right\}=\frac{\alpha_{2}}{\gamma_{2} c_{2}}-\varepsilon$ and $r_{\text {Case } C}^{*}<\frac{\alpha_{2}}{\gamma_{2} c_{2}}-\varepsilon$, then the optimal values are obtained as:

$$
\begin{gathered}
t_{1}^{*}=\frac{c_{2} \gamma_{2}}{\alpha_{2} \gamma_{1}}-\frac{c_{1}}{\alpha_{1}}, t_{2}^{*}=0, r^{*}=\frac{\alpha_{2}}{\gamma_{2} c_{2}}-\varepsilon \\
U_{C_{1}}^{*}=\frac{1}{\left(e^{\frac{c_{1}}{\alpha_{1}}}+e^{\frac{c_{2} \gamma_{2}}{\alpha_{2} \gamma_{1}}}\right)^{2}}, U_{C_{2}}^{*}=\frac{1}{4} e^{\frac{-2 c_{2}}{\alpha_{2}}} \\
U_{O E M}^{*(H)}=\rho\left(2-\xi c_{1}+\frac{\xi c_{1}}{\alpha_{1}}\right)-\frac{\rho \xi c_{2}\left(\alpha_{2} \gamma_{1}+\gamma_{2}\right)}{\alpha_{2} \gamma_{1}}+2\left(\varepsilon-\frac{\alpha_{2}}{c_{2} \gamma_{2}}\right)
\end{gathered}
$$

And the feasible range for this case is $F R_{H}=\left\{\rho \gamma_{2} c_{1} \xi\left(\gamma_{1}+\gamma_{2}\right)-2 \gamma_{1} \alpha_{2}^{2}>0,2 \gamma_{1} \alpha_{2}^{2}-\rho \xi \gamma_{2}{ }^{2} c_{2}^{2}>0, \alpha_{2}-\varepsilon \gamma_{2} c_{2}>0, \gamma_{1} c_{1} \alpha_{2}\right.$ $\left.-\gamma_{2} c_{2} \alpha_{1} \geq 0\right\}$.

Case I: When $r_{\text {Case A }}^{*}>\min \left\{\frac{\alpha_{1}}{\gamma_{1} c_{1}}-\varepsilon, \frac{\alpha_{2}}{\gamma_{2} c_{2}}-\varepsilon\right\}=\frac{\alpha_{1}}{\gamma_{1} c_{1}}-\varepsilon$ and $r_{\text {Case } E}^{*}<\frac{\alpha_{1}}{\gamma_{1} c_{1}}-\varepsilon$. Then the optimal values are obtained as:

$$
t_{1}^{*}=0, t_{2}^{*}=\frac{c_{1} \gamma_{1}}{\alpha_{1} \gamma_{2}}-\frac{c_{2}}{\alpha_{2}}, r^{*}=\frac{\alpha_{1}}{\gamma_{1} c_{1}}-\varepsilon
$$




$$
\begin{gathered}
U_{C_{1}}^{*}=\frac{1}{4} e^{\frac{-2 c_{1}}{\alpha_{1}}}, U_{C_{2}}^{*}=\frac{1}{\left(e^{\frac{c_{2}}{\alpha_{2}}}+e^{\frac{c_{1} \gamma_{1}}{\alpha_{\gamma_{2}}}}\right)^{2}} \\
U_{O E M}^{*(H)}=\rho\left(2-\xi c_{2}+\frac{\xi c_{2}}{\alpha_{2}}\right)-\frac{\rho \xi c_{1}\left(\alpha_{1} \gamma_{2}+\gamma_{1}\right)}{\alpha_{1} \gamma_{2}}+2\left(\varepsilon-\frac{\alpha_{1}}{c_{1} \gamma_{1}}\right)
\end{gathered}
$$

And the feasible range for this case is $F R_{I}=\left\{\rho \gamma_{1} c_{1} \xi\left(\gamma_{1}+\gamma_{2}\right)-2 \gamma_{2} \alpha_{1}^{2}>0,2 \gamma_{2} \alpha_{1}^{2}-\rho \xi \gamma_{1}^{2} c_{1}^{2}>0, \alpha_{1}-\varepsilon \gamma_{1} c_{1}>0, \gamma_{2} c_{2} \alpha_{1}\right.$ $\left.-\gamma_{1} c_{1} \alpha_{2} \geq 0\right\}$.

\section{A.2.2 Proof of the Optimal Region for the Game between Two Consumers}

According to the feasibility ranges and corresponding optimal values, there may be several feasible equilibrium cases for a specific combination set of parameters. We define the optimal range of Case $I$ as:

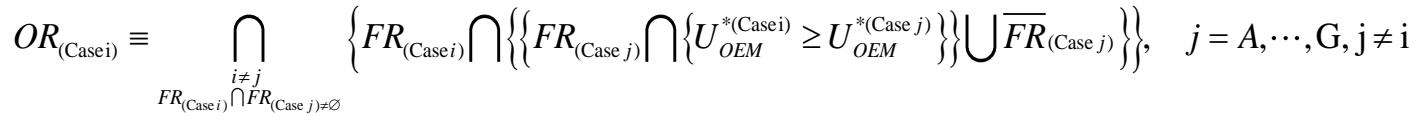

Case A: Since $F R_{A} \cap F R_{j}=\varnothing, \forall j \in\{B, H, I\}$, it is not required to compare $U_{O E M}^{*(A)}$ with the $U_{O E M}^{*(B)}, U_{O E M}^{*(H)}$ and $U_{O E M}^{*(I)}$. Therefore, the optimal range for Case $A$ is obtained as:

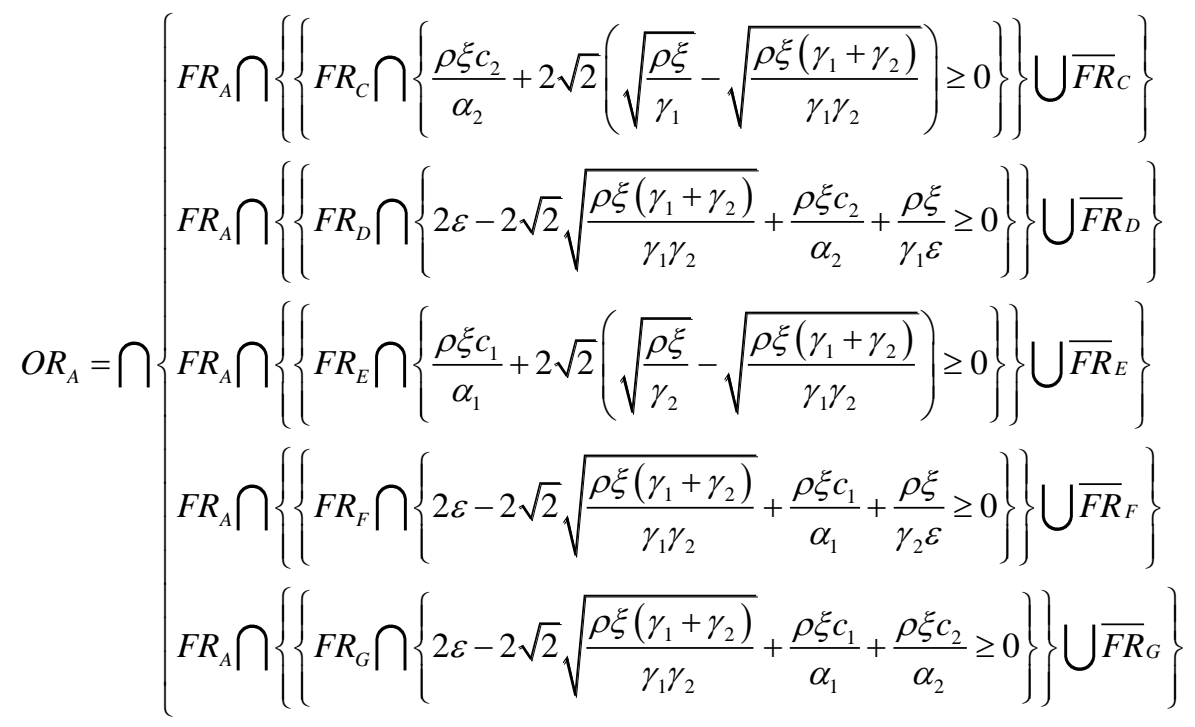

To simplify $O R_{(\text {Casei })}$, we define function $F$ as:

$$
\begin{aligned}
F\left(x_{1}, x_{2}, x_{3}, x_{4}, x_{5}, x_{6}, x_{7}, x_{8}\right)= & x_{1} 2 \varepsilon+x_{2} \frac{\rho \xi c_{1}}{\alpha_{1}}+x_{3} \frac{\rho \xi c_{2}}{\alpha_{2}}+x_{4} 2 \sqrt{\frac{2 \rho \xi\left(\gamma_{1}+\gamma_{2}\right)}{\gamma_{1} \gamma_{2}}}+x_{5} 2 \sqrt{\frac{2 \rho \xi}{\gamma_{1}}}+x_{6} 2 \sqrt{\frac{2 \rho \xi}{\gamma_{2}}}+ \\
& x_{7} \frac{\rho \xi}{\gamma_{1} \varepsilon}+x_{8} \frac{\rho \xi}{\gamma_{2} \varepsilon}
\end{aligned}
$$

So after simplification, $O R_{A}$ is obtained as $O R_{A}=F R_{A} \cap\left\{F R_{C} \cap\{\{F(0,0,1,-1,1,0,0,0) \geq 0\} \cup \overline{F R} C\}\right\}\left\{F R_{D} \cap\right.$ $\left.\left\{\{F(1,0,1,-1,0,0,1,0) \geq 0\} \cup \overline{F R}_{D}\right\}\right\} \cap\left\{F R_{E} \cap\left\{\{F(0,1,0,-1,0,1,0,0) \geq 0\} \cup \overline{F R}_{E}\right\}\right\} \cap\left\{F R_{F} \cap\left\{\{F(1,1,0,-1,0,0,0,1) \geq 0\} \cup \overline{F R}_{F}\right\}\right.$ $\bigcap\left\{F R_{G} \cap\left\{\{F(1,1,1,-1,0,0,0,0) \geq 0\} \cup \overline{F R}_{G}\right\}\right\}$. 
Case B: In this case, we only need to compare $U_{O E M}^{*(B)}$ with $U_{O E M}^{*(\mathrm{C})}$ and $U_{O E M}^{*(\mathrm{E})}$ because $F R_{B} \cap F R_{j}=\varnothing, \forall j \in S \backslash\{B, C, E\}$, where $S$ is the set of all cases. So, the optimal range for Case $B$ is:

$$
O R_{B}=\bigcap\left\{\begin{array}{l}
F R_{B} \bigcap\left\{\left\{F R_{C} \bigcap\left\{\frac{\rho \xi c_{2}}{\alpha_{2}}+2 \sqrt{2} \sqrt{\frac{\rho \xi}{\gamma_{1}}}-2 \varepsilon-\frac{\rho \xi}{\varepsilon}\left(\frac{1}{\gamma_{1}}+\frac{1}{\gamma_{2}}\right) \geq 0\right\}\right\} \bigcup \overline{F R}_{C}\right\} \\
F R_{B} \bigcap\left\{\left\{F R_{E} \bigcap\left\{\frac{\rho \xi c_{1}}{\alpha_{1}}+2 \sqrt{2} \sqrt{\frac{\rho \xi}{\gamma_{2}}}-2 \varepsilon-\frac{\rho \xi}{\varepsilon}\left(\frac{1}{\gamma_{1}}+\frac{1}{\gamma_{2}}\right) \geq 0\right\}\right\} \bigcup \overline{F R}_{E}\right\}
\end{array}\right.
$$

The simplified optimal region is $O R_{B}=F R_{B} \cap\left\{F R_{C} \cap\{\{F(-1,0,1,0,1,0,-1,-1) \geq 0\} \cup \overline{F R} C\}\right\} \cap\left\{F R_{E}\right.$ $\left.\cap\left\{\{F(-1,1,0,0,0,1,-1,-1) \geq 0\} \cup \overline{F R}_{E}\right\}\right\}$.

Case C: Since $F R_{C} \cap F R_{j}=\varnothing, \forall j \in\{D, F, H, I\}$. Then, the optimal range $O R_{C}$ is defined as:

$$
O R_{C}=\bigcap\left\{\begin{array}{l}
\left.F R_{C} \bigcap\left\{f F R_{A} \bigcap\left\{2 \sqrt{2}\left(\sqrt{\frac{\rho \xi\left(\gamma_{1}+\gamma_{2}\right)}{\gamma_{1} \gamma_{2}}}-\sqrt{\frac{\rho \xi}{\gamma_{1}}}\right)-\frac{\rho \xi c_{2}}{\alpha_{2}} \geq 0\right\}\right\} \bigcup \overline{F R}_{A}\right\} \\
F R_{C} \bigcap\left\{\left\{F R_{B} \bigcap\left\{2 \sqrt{2} \sqrt{\frac{\rho \xi\left(\gamma_{1}+\gamma_{2}\right)}{\gamma_{1} \gamma_{2}}}-\frac{\rho \xi c_{2}}{\alpha_{2}}-\frac{\rho \xi}{\gamma_{1} \varepsilon}-2 \varepsilon \geq 0\right\}\right\} \bigcup \overline{F R}_{B}\right\} \\
F R_{C} \bigcap\left\{\left\{F R_{E} \bigcap\left\{2 \sqrt{2}\left(\sqrt{\frac{\rho \xi}{\gamma_{2}}}-\sqrt{\frac{\rho \xi}{\gamma_{1}}}\right)+\rho \xi\left(\frac{c_{2}}{\alpha_{2}}-\frac{c_{1}}{\alpha_{1}}\right) \geq 0\right\}\right\} \bigcup \overline{F R}_{E}\right\} \\
F R_{C} \bigcap\left\{\left\{F R_{G} \bigcap\left\{2 \varepsilon+\frac{\rho \xi c_{1}}{\alpha_{1}}-2 \sqrt{2} \sqrt{\frac{\rho \xi}{\gamma_{1}}} \geq 0\right\}\right\} \bigcup \overline{F R}_{G}\right\}
\end{array}\right.
$$

Then after simplification, we have $O R_{C}=F R_{C} \cap\left\{F R_{A} \cap\left\{\{F(0,0,-1,1,-1,0,0,0) \geq 0\} \cup \overline{F R}_{A}\right\}\right\} \cap\left\{F R_{B} \cap\right.$ $\left.\left\{\{\mathrm{F}(-1,0,-1,1,0,0,1,0) \geq 0\} \cup \overline{\mathrm{FR}}_{\mathrm{B}}\right\}\right\} \cap\left\{\mathrm{FR}_{\mathrm{E}} \cap\left\{\{\mathrm{F}(0,-1,1,0,-1,1,0,0) \geq 0\} \cup \overline{\mathrm{FR}}_{\mathrm{E}}\right\}\right\} \cap\left\{\mathrm{FR}_{\mathrm{G}} \cap\left\{\{\mathrm{F}(1,1,0,0,-1,0,0,0) \geq 0\} \cup \overline{\mathrm{FR}}_{\mathrm{G}}\right\}\right\}$.

Case D: In this case we only need to compare $U_{O E M}^{*(\mathrm{D})}$ with $U_{O E M}^{*(A)}$ because $F R_{D} \cap F R_{j}=\varnothing, \forall j \in S \backslash\{A, D\}$. So, the optimal range for Case $D$ is:

$$
O R_{D}=F R_{D} \bigcap\left\{\left\{F R_{A} \bigcap\left\{2 \sqrt{2} \sqrt{\frac{\rho \xi\left(\gamma_{1}+\gamma_{2}\right)}{\gamma_{1} \gamma_{2}}}-2 \varepsilon-\frac{\rho \xi c_{2}}{\alpha_{2}}-\frac{\rho \xi}{\gamma_{1} \varepsilon} \geq 0\right\}\right\} \bigcup \overline{F R}_{A}\right\}
$$

The simplified optimal region is $O R_{D}=F R_{D} \cap\left\{F R_{A} \cap\left\{\{F(-1,0,-1,1,0,0,-1,0) \geq 0\} \cup \overline{F R}_{A}\right\}\right\}$.

Case E: Because $F R_{E} \cap F R_{j}=\varnothing, \forall j \in\{\mathrm{D}, \mathrm{F}, H, I\}$. Then, the optimal range $O R_{E}$ is obtained as: 


$$
O R_{E}=\bigcap\left\{\begin{array}{l}
F R_{E} \bigcap\left\{\left\{F S_{A} \bigcap\left\{2 \sqrt{2}\left(\sqrt{\frac{\rho \xi\left(\gamma_{1}+\gamma_{2}\right)}{\gamma_{1} \gamma_{2}}}-\sqrt{\frac{\rho \xi}{\gamma_{2}}}\right)-\frac{\rho \xi c_{1}}{\alpha_{1}} \geq 0\right\}\right\} \bigcup \overline{F R}_{A}\right\} \\
F R_{E} \bigcap\left\{\left\{F S_{B} \bigcap\left\{\frac{\rho \xi}{\varepsilon}\left(\frac{1}{\gamma_{1}}+\frac{1}{\gamma_{2}}\right)+2 \varepsilon-\frac{\rho \xi c_{1}}{\alpha_{1}}-2 \sqrt{2} \sqrt{\frac{\rho \xi}{\gamma_{2}}} \geq 0\right\}\right\} \bigcup \overline{F R}_{B}\right\} \\
F R_{E} \bigcap\left\{\left\{F S_{C} \bigcap\left\{2 \sqrt{2}\left(\sqrt{\frac{\rho \xi}{\gamma_{1}}}-\sqrt{\frac{\rho \xi}{\gamma_{2}}}\right)+\rho \xi\left(\frac{c_{1}}{\alpha_{1}}-\frac{c_{2}}{\alpha_{2}}\right) \geq 0\right\}\right\} \bigcup \overline{F R}_{C}\right\} \\
F R_{E} \bigcap\left\{\left\{F S_{G} \bigcap\left\{2 \varepsilon+\frac{\rho \xi c_{2}}{\alpha_{2}}-2 \sqrt{2} \sqrt{\frac{\rho \xi}{\gamma_{2}}} \geq 0\right\}\right\} \bigcup \overline{F R}_{G}\right\}
\end{array}\right.
$$

The simplified optimal region is $O R_{E}=F R_{E} \cap\left\{F R_{A} \cap\left\{\{F(0,-1,0,1,0,-1,0,0) \geq 0\} \cup \overline{F R}_{A}\right\}\right\} \cap\left\{F R_{B} \cap\right.$ $\left.\left\{\{F(1,-1,0,0,0,-1,1,1) \geq 0\} \cup \overline{F R}_{B}\right\}\right\} \cap\left\{F R_{C} \cap\left\{\{F(0,1,-1,0,1,-1,0,0) \geq 0\} \cup \overline{F R}_{C}\right\}\right\} \cap\left\{F R_{G} \cap\left\{\{F(1,0,-1,1,0,0,-1,0) \geq 0\} \cup \overline{F R}_{G}\right\}\right\}$.

Case F: In this case, we only need to compare $U_{O E M}^{*(\mathrm{~F})}$ with $U_{O E M}^{*(A)}$ because $F R_{F} \cap F R_{j}=\varnothing, \forall j \in S \backslash\{A, F\}$. So, the optimal range for Case $F$ can be obtained as:

$$
F R_{F}=F R_{F} \bigcap\left\{\left\{F R_{A} \bigcap\left\{2 \sqrt{2} \sqrt{\frac{\rho \xi\left(\gamma_{1}+\gamma_{2}\right)}{\gamma_{1} \gamma_{2}}}-\frac{\rho \xi c_{1}}{\alpha_{1}}-\frac{\rho \xi}{\gamma_{2} \varepsilon}-2 \varepsilon \geq 0\right\}\right\} \bigcup \overline{F R}_{A}\right\}
$$

The optimal range for this case is $O R_{F}=F R_{F} \cap\left\{F R_{A} \cap\left\{\{F(-1,-1,0,1,0,0,0,-1) \geq 0\} \cup \overline{F R}_{A}\right\}\right\}$.

$\underline{\text { Case } G}$ : In this case, we only need to compare $U_{O E M}^{*(G)}$ with $U_{O E M}^{*(A)}, U_{O E M}^{*(C)}$ and $U_{O E M}^{*(E)}$ because $F R_{G} \cap F R_{j}=\varnothing, \forall j \in S \backslash\{A, C, E, G\}$. So, the optimal range for Case $G$ can be obtained as:

$$
O R_{G}=\left\{\begin{array}{l}
F R_{G} \bigcap\left\{\left\{F R_{A} \bigcap\left\{2 \sqrt{2} \sqrt{\frac{\rho \xi\left(\gamma_{1}+\gamma_{2}\right)}{\gamma_{1} \gamma_{2}}}-2 \varepsilon-\frac{\rho \xi c_{1}}{\alpha_{1}}-\frac{\rho \xi c_{2}}{\alpha_{2}} \geq 0\right\}\left\{\bigcup R_{C} \bigcap\left\{2 \sqrt{2} \sqrt{\frac{\rho \xi}{\gamma_{1}}}-2 \varepsilon-\frac{\rho \xi c_{1}}{\alpha_{1}} \geq 0\right\}\right\} \bigcup \overline{F R}_{C}\right\}\right. \\
F R_{G} \bigcap\left\{\left\{F R_{E} \bigcap\left\{2 \sqrt{2} \sqrt{\frac{\rho \xi}{\gamma_{2}}}-2 \varepsilon-\frac{\rho \xi c_{2}}{\alpha_{2}} \geq 0\right\}\right\} \bigcup \overline{F R}_{E}\right\}
\end{array}\right.
$$

The optimal range is simplified as $O R_{G}=F R_{G} \cap\left\{F R_{A} \cap\left\{\{F(-1,-1,-1,1,0,0,0,0) \geq 0\} \cup F R_{A}\right\}\right\} \cap\left\{F R_{C} \cap\{\{F\right.$ $\left.\left.(-1,-1,0,0,1,0,0,0) \geq 0\} \cup \overline{F R}_{C}\right\}\right\} \cap\left\{F R_{E} \cap\left\{\{F(-1,0,-1,0,0,1,0,0) \geq 0\} \cup \overline{F R}_{E}\right\}\right\}$.

Case H: Since $F R_{H} \cap F R_{j}=\varnothing, \forall j \in S$, then $O R_{H}=F R_{H}$.

Case I: Since $F R_{I} \cap F R_{j}=\varnothing, \forall j \in S$, then $O R_{I}=F R_{I}$.

\section{A.3 Proof of Theorem 3}

\section{A.3.1 Proof of Equilibrium Solutions for the Case of $N$ Homogeneous Consumers}

To prove Theorem 3, we follow the proof of Theorem 2. As mentioned in Sec. 3, we have three cases of equilibrium: 
(i) When $t_{i}^{*}=t^{*}>0, \forall i=1, \ldots, N$. Then, the optimal value of the storage time $t^{*}$ is $\frac{1}{\bar{\gamma}\left(r^{*}+\varepsilon\right)}-\frac{\bar{c}}{\bar{\alpha}}$. Then, the utility function of the OEM is obtained as:

$$
U_{\text {OEM }}\left(r^{*}\right)=N \rho\left(1-\xi\left(\frac{1}{\bar{\gamma}\left(r^{*}+\varepsilon\right)}+\bar{c}\left(1-\frac{1}{\bar{\alpha}}\right)\right)\right)-N r^{*}
$$

The best value of the incentive value is obtained as:

$$
r^{*}= \begin{cases}\sqrt{\frac{\rho \xi}{\bar{\gamma}}}-\varepsilon & \text { if } \sqrt{\frac{\rho \xi}{\bar{\gamma}}}>\varepsilon \\ 0 & \text { if } \sqrt{\frac{\rho \xi}{\bar{\gamma}}} \leq \varepsilon\end{cases}
$$

Case A: If $r^{*}>0$, Case $A$ is achieved as:

$$
\begin{aligned}
& t_{i}^{*}=t^{*}=\frac{1}{\sqrt{\bar{\gamma} \rho \xi}}-\frac{\bar{c}}{\bar{\alpha}}, r^{*}=\sqrt{\frac{\rho \xi}{\bar{\gamma}}}-\varepsilon, \forall i=1, \ldots, N . \\
& U_{C_{i}}^{*}=\frac{1}{4} e^{-\frac{\bar{c}}{\bar{\alpha}}-\frac{1}{\sqrt{\bar{p} \rho \xi}}}, \forall i=1, \ldots, N . \\
& U_{O E M}^{*(\mathrm{~A})}=\frac{N\left(\rho \bar{c} \xi+\bar{\alpha}\left(\varepsilon+\rho-\rho \bar{c} \xi-2 \sqrt{\frac{\rho \xi}{\bar{\gamma}}}\right)\right)}{\bar{\alpha}}
\end{aligned}
$$

And the feasibility range $F R_{A}=\left\{\bar{\alpha}^{2}-\bar{c}^{2} \bar{\gamma} \rho \xi>0, \rho \xi-\varepsilon^{2} \bar{\gamma}>0\right\}$.

Case $B$ : If $r^{*}=0$, the optimal values are found as:

$$
\begin{gathered}
t_{i}^{*}=\bar{t}=\frac{1}{\bar{\gamma} \varepsilon}-\frac{\bar{c}}{\bar{\alpha}}, r^{*}=0, \forall i=1, \ldots, N . \\
U_{C_{i}}^{*(\mathrm{~B})}=\frac{1}{4} e^{-\frac{\bar{c}}{\bar{\alpha}}-\frac{1}{\bar{\gamma}}}, \forall i=1, \ldots, N . \\
U_{O E M}^{*}=N \rho\left(1-\xi\left(\frac{1}{\bar{\gamma} \varepsilon}+\bar{c}\left(1-\frac{1}{\bar{\alpha}}\right)\right)\right)
\end{gathered}
$$

And the feasible range is obtained as $F R_{B}=\left\{\varepsilon^{2} \bar{\gamma}-\rho \xi \geq 0, \bar{\alpha}-\varepsilon \bar{\gamma} \bar{c}>0\right\}$.

(ii) If $t_{i}^{*}=t^{*}=0, \forall i=1, \ldots, N$, the OEM does not consider an incentive since any positive value decreases the utility function.

$$
U_{O E M}\left(r^{*}\right)=N \rho(1-\xi \bar{c})-N r^{*}
$$

Case $C$ : when $t_{i}^{*}=t^{*}=0, \forall i=1, \ldots, N$, Case $C$ can be obtained as:

$$
\begin{gathered}
t_{i}^{*}=t^{*}=0, r^{*}=0, \forall i=1, \ldots, N . \\
U_{C_{i}}^{*}=\frac{1}{\left(e^{\frac{\overline{\bar{\alpha}}}{\bar{\alpha}}}+e^{\frac{1}{\bar{\gamma} \delta}}\right)^{2}}, \forall i=1, \ldots, N . \\
U_{O E M}^{*(\mathrm{C})}=N \rho(1-\xi \bar{c})
\end{gathered}
$$

And the feasibility range is obtained as $F S_{C}=\{\varepsilon \bar{\gamma} \bar{c}-\bar{\alpha} \geq 0\}$.

\section{A.3.2 Proof of Optimal Region for the Case of $N$ Homogeneous Consumers}

The proof is similar to the one in A.2.2. 
$\underline{\text { Case A: }}$ In this case, we need to compare $U_{O E M}^{*(A)}$ with $U_{O E M}^{*(\mathrm{C})}$ since $F R_{A} \cap F R_{B}=\varnothing$. So, $O R_{A}$ is obtained as:

$$
\left.O R_{A}=F R_{A} \bigcap\left\{F R_{C} \bigcap\left\{\frac{N\left(\rho \bar{c} \xi+\bar{\alpha}\left(\varepsilon+\rho-\rho \bar{c} \xi-2 \sqrt{\frac{\rho \xi}{\bar{\gamma}}}\right)\right)}{\bar{\alpha}}-N \rho(1-\xi \bar{c}) \geq 0\right\}\right\} \bigcup \overline{F R}_{C}\right\}
$$

After simplifying, the optimal range is $O R_{A}=F R_{A} \bigcap\left\{\left\{F R_{C} \bigcap\left\{\rho \bar{c} \xi+\bar{\alpha} \varepsilon-2 \bar{\alpha} \sqrt{\frac{\rho \xi}{\bar{\gamma}}} \geq 0\right\}\right\} \bigcup \overline{F R_{C}}\right\}$.

Case B: Since $F R_{B} \cap F R_{j}=\varnothing, \forall j \in S \backslash\{B\}$, then the optimal range is $O R_{B}=F R_{B}$.

Case $C$ : In this case, we need to compare $U_{O E M}^{*(C)}$ with $U_{O E M}^{*(A)}$ since $F R_{C} \cap F R_{B}=\varnothing$. So, $O R_{C}$ is obtained as:

$$
\left.O R_{C}=F R_{C} \bigcap\left\{F R_{A} \bigcap\left\{N \rho(1-\xi \bar{c})-\frac{N\left(\rho \bar{c} \xi+\bar{\alpha}\left(\varepsilon+\rho-\rho \bar{c} \xi-2 \sqrt{\frac{\rho \xi}{\bar{\gamma}}}\right)\right)}{\bar{\alpha}} \geq 0\right\}\right\} \bigcup \overline{F R}_{A}\right\}
$$

Finally, the optimal range is $\left.O R_{C}=F R_{C} \bigcap\left\{f R_{A} \bigcap\left\{2 \bar{\alpha} \sqrt{\frac{\rho \xi}{\bar{\gamma}}}-\rho \bar{c} \xi-\bar{\alpha} \varepsilon \geq 0\right\}\right\} \bigcup \overline{F R_{A}}\right\}$.

\section{References}

[1] H. Veit and A. Bernardes, "Electronic Waste: Generation and Management," in Electronic Waste SE - 2, H. M. Veit and A. Moura Bernardes, Eds. Springer International Publishing, 2015, pp. 3-12.

[2] N. Truttmann and H. Rechberger, "Contribution to resource conservation by reuse of electrical and electronic household appliances," Resour. Conserv. Recycl., vol. 48, no. 3, pp. 249-262, 2006.

[3] R. Lifset, A. Atasu, and N. Tojo, "Extended Producer Responsibility," J. Ind. Ecol., vol. 17, no. 2, pp. 162-166, 2013.

[4] J. A. Bhatti, "Current state and potential for increasing plastics recycling in the US." Columbia University, 2010.

[5] M. Sabbaghi, B. Esmaeilian, and A. Mashhadi, "An investigation of used electronics return flows: A data-driven approach to capture and predict consumers storage and utilization behavior," Waste Manag., vol. 36, pp. 305-15, 2015.

[6] J.-D. M. Saphores, H. Nixon, O. A. Ogunseitan, and A. A. Shapiro, "Household willingness to recycle electronic waste an application to California," Environ. Behav., vol. 38, no. 2, pp. 183208, 2006.

[7] D. Das and P. Dutta, "Simulation study of an integrated reverse logistics in fuzzy environment," in IAENG Transactions on Engineering Technologies, Springer, 2013, pp. 151165. 
[8] R. Geyer and V. D. Blass, "The economics of cell phone reuse and recycling," Int. J. Adv. Manuf. Technol., vol. 47, no. 5-8, pp. 515-525, 2010.

[9] K. L. Haws, R. W. Naylor, R. A. Coulter, and W. O. Bearden, "Keeping it all without being buried alive: Understanding product retention tendency," J. Consum. Psychol., vol. 22, no. 2, pp. 224-236, Apr. 2012.

[10] A. Ovchinnikov, "Revenue and cost management for remanufactured products," Prod. Oper. Manag., vol. 20, no. 6, pp. 824-840, 2011.

[11] S. K. Jena and S. P. Sarmah, "Price competition and co-operation in a duopoly closed-loop supply chain,” Int. J. Prod. Econ., vol. 156, pp. 346-360, 2014.

[12] D. Kahneman, J. L. Knetsch, and R. H. Thaler, "Anomalies: The Endowment Effect, Loss Aversion, and Status Quo Bias,” J. Econ. Perspect., vol. 5, no. 1, pp. 193-206, 1991.

[13] V. D. R. Guide and L. U. K. N. Van Wassenhove, "Managing Product Returns For Remanufacturing," Prod. Oper. Manag., vol. 10, no. 2, pp. 142-155, Jun. 2001.

[14] A. Atasu, V. D. R. Guide, and L. N. Wassenhove, "Product reuse economics in closed- loop supply chain research," Prod. Oper. Manag., vol. 17, no. 5, pp. 483-496, 2008.

[15] J.-P. Kenné, P. Dejax, and A. Gharbi, "Production planning of a hybrid manufacturingremanufacturing system under uncertainty within a closed-loop supply chain," Int. J. Prod. Econ., vol. 135, no. 1, pp. 81-93, Jan. 2012.

[16] K. Inderfurth, "Optimal policies in hybrid manufacturing/remanufacturing systems with product substitution," Int. J. Prod. Econ., vol. 90, no. 3, pp. 325-343, Aug. 2004.

[17] R. Teunter, K. Kaparis, and O. Tang, "Multi-product economic lot scheduling problem with separate production lines for manufacturing and remanufacturing," Eur. J. Oper. Res., vol. 191, no. 3, pp. 1241-1253, Dec. 2008.

[18] E. Bazan, M. Y. Jaber, and A. M. A. El Saadany, "Carbon emissions and energy effects on manufacturing-remanufacturing inventory models," Comput. Ind. Eng., vol. 88, pp. 307-316, Oct. 2015.

[19] N. Aras, D. Aksen, and M. T. Tekin, "Selective multi-depot vehicle routing problem with pricing," Transp. Res. Part C Emerg. Technol., vol. 19, no. 5, pp. 866-884, 2011.

[20] D. Aksen, N. Aras, and A. G. Karaarslan, "Design and analysis of government subsidized collection systems for incentive-dependent returns," Int. J. Prod. Econ., vol. 119, no. 2, pp. 308-327, Jun. 2009.

[21] C.-H. Wu, "Product-design and pricing strategies with remanufacturing," Eur. J. Oper. Res., vol. 222, no. 2, pp. 204-215, Oct. 2012.

[22] P. Kulshreshtha and S. Sarangi, “No return, no refund': an analysis of deposit-refund systems," J. Econ. Behav. Organ., vol. 46, no. 4, pp. 379-394, Dec. 2001.

[23] V. D. R. Guide Jr, R. H. Teunter, and L. N. Van Wassenhove, "Matching demand and supply to maximize profits from remanufacturing," Manuf. Serv. Oper. Manag., vol. 5, no. 4, pp. 303-316, 2003. 
[24] D. Hammond and P. Beullens, "Closed-loop supply chain network equilibrium under legislation,” Eur. J. Oper. Res., vol. 183, no. 2, pp. 895-908, Dec. 2007.

[25] I. S. Bakal and E. Akcali, "Effects of Random Yield in Remanufacturing with Price-Sensitive Supply and Demand," Prod. Oper. Manag., vol. 15, no. 3, pp. 407-420, Sep. 2006.

[26] S. Ray, T. Boyaci, and N. Aras, "Optimal prices and trade-in rebates for durable, remanufacturable products," Manuf. Serv. Oper. Manag., vol. 7, no. 3, pp. 208-228, 2005.

[27] J. Ylä-Mella, R. L. Keiski, and E. Pongrácz, "Electronic waste recovery in Finland: Consumers' perceptions towards recycling and re-use of mobile phones," Waste Manag., vol. 45, pp. 374-384, Nov. 2015.

[28] R. Ayres, G. Ferrer, and T. Van Leynseele, "Eco-efficiency, asset recovery and remanufacturing," Eur. Manag. J., vol. 15, no. 5, pp. 557-574, 1997.

[29] S. K. Jena and S. P. Sarmah, "Measurement of consumers' return intention index towards returning the used products," J. Clean. Prod., vol. 108, Part , pp. 818-829, Dec. 2015.

[30] A. R. Mashhadi, B. Esmaeilian, and S. Behdad, "Uncertainty Management in Remanufacturing Decisions: A Consideration of Uncertainties in Market Demand, Quantity, and Quality of Returns," ASCE-ASME J. Risk Uncertain. Eng. Syst. Part B Mech. Eng., vol. 1, no. 2, p. 21007, 2015.

[31] S. Agrawal, R. K. Singh, and Q. Murtaza, "Forecasting product returns for recycling in Indian electronics industry," J. Adv. Manag. Res., vol. 11, no. 1, pp. 102-114, 2014.

[32] S. M. Budijati, M. A. Wibisono, and N. A. Masruroh, "A Study of Consumers' Post Consumption Behaviour for Mobile Phone in Indonesia," in Industrial Engineering, Management Science and Applications 2015, Springer, 2015, pp. 563-573.

[33] C. Witek, "Return Management for Remanufacturing," in Logistics Management SE - 6, J. Dethloff, H.-D. Haasis, H. Kopfer, H. Kotzab, and J. Schönberger, Eds. Springer International Publishing, 2015, pp. 67-80.

[34] Y. Guo and J. Ma, "Research on game model and complexity of retailer collecting and selling in closed-loop supply chain," Appl. Math. Model., vol. 37, no. 7, pp. 5047-5058, 2013.

[35] J. Ma and H. Wang, "Complexity analysis of dynamic noncooperative game models for closed-loop supply chain with product recovery," Appl. Math. Model., vol. 38, no. 23, pp. 5562-5572, 2014.

[36] P. Zhang, Y. Xiong, Z. Xiong, and W. Yan, "Designing contracts for a closed-loop supply chain under information asymmetry," Oper. Res. Lett., vol. 42, no. 2, pp. 150-155, Mar. 2014.

[37] K. Jung and H. Hwang, "Competition and cooperation in a remanufacturing system with takeback requirement," J. Intell. Manuf., vol. 22, no. 3, pp. 427-433, 2011.

[38] J.-B. Sheu and Y. J. Chen, "Impact of government financial intervention on competition among green supply chains," Int. J. Prod. Econ., vol. 138, no. 1, pp. 201-213, 2012.

[39] F. Zhang and P. R. Zhang, "Trade-in remanufacturing, strategic customer behavior, and government subsidies," Strateg. Cust. Behav. Gov. Subsid. (February 22, 2015), 2015. 
[40] C.-H. Wu, "Strategic and operational decisions under sales competition and collection competition for end-of-use products in remanufacturing," Int. J. Prod. Econ., vol. 169, pp. 11$20,2015$.

[41] T. S. Genc and P. De Giovanni, "Trade-in and save: A two-period closed-loop supply chain game with price and technology dependent returns," Int. J. Prod. Econ., 2016.

[42] M. Sabbaghi, B. Esmaeilian, A. Raihanian Mashhadi, W. Cade, and S. Behdad, "Reusability Assessment of Lithium-ion Laptop Batteries Based on Consumers Actual Usage Behavior," J. Mech. Des., Sep. 2015.

[43] P. Manomaivibool and S. Vassanadumrongdee, "Buying back household waste electrical and electronic equipment: Assessing Thailand's proposed policy in light of past disposal behavior and future preferences," Resour. Conserv. Recycl., vol. 68, pp. 117-125, 2012.

[44] A. Atasu and L. N. Wassenhove, "An Operations Perspective on Product Take- Back Legislation for E- Waste: Theory, Practice, and Research Needs," Prod. Oper. Manag., vol. 21, no. 3, pp. 407-422, 2012.

[45] Q. Zhu and J. Sarkis, "Green marketing and consumerism as social change in China: Analyzing the literature," Int. J. Prod. Econ.

[46] T. Iwase and T. Shiga, "Linear Game Theory: Reduction of complexity by decomposing large games into partial games," arXiv Prepr. arXiv1609.00481, 2016.

[47] J. Zhuang, "Impacts of subsidized security on stability and total social costs of equilibrium solutions in an n-player game with errors," Eng. Econ., vol. 55, no. 2, pp. 131-149, 2010.

[48] M. Kwak, S. Behdad, Y. Zhao, H. Kim, and D. Thurston, "E-Waste Stream Analysis and Design Implications,” J. Mech. Des., vol. 133, no. 10, p. 101003, Sep. 2011.

[49] Y. Gu, Y. Wu, M. Xu, H. Wang, and T. Zuo, "The stability and profitability of the informal WEEE collector in developing countries: A case study of China," Resour. Conserv. Recycl., vol. 107, pp. 18-26, 2016.

[50] J.-D. M. Saphores, O. A. Ogunseitan, and A. A. Shapiro, "Willingness to engage in a proenvironmental behavior: An analysis of e-waste recycling based on a national survey of U.S. households," Resour. Conserv. Recycl., vol. 60, no. 0, pp. 49-63, Mar. 2012.

[51] C.-J. Chung and H.-M. Wee, "Short life-cycle deteriorating product remanufacturing in a green supply chain inventory control system," Int. J. Prod. Econ., vol. 129, no. 1, pp. 195-203, Jan. 2011.

[52] M. Kwak, H. Kim, and D. Thurston, "Formulating Second-Hand Market Value as a Function of Product Specifications, Age, and Conditions," J. Mech. Des., vol. 134, no. 3, p. 32001, Mar. 2012.

[53] H. Koo and K. Janigo, "Development of conductive gloves for touchscreen devices," Int. J. Fash. Des. Technol. Educ., pp. 1-10, 2016.

[54] A. Mutha, S. Bansal, and V. D. R. Guide, "Managing Demand Uncertainty through Core Acquisition in Remanufacturing," Prod. Oper. Manag., 2016. 
[55] D. M. Ford, "Technologizing Africa: On the bumpy information highway," Comput. Compos., vol. 24, no. 3, pp. 302-316, 2007.

[56] X. Shan and J. Zhuang, "Modeling Credible Retaliation Threats in Deterring the Smuggling of Nuclear Weapons Using Partial Inspection-A Three-Stage Game," Decis. Anal., vol. 11, no. 1, pp. 43-62, 2014.

[57] C.-C. Chen, H.-S. Shih, H.-J. Shyur, and K.-S. Wu, "A business strategy selection of green supply chain management via an analytic network process," Comput. Math. with Appl., vol. 64, no. 8, pp. 2544-2557, 2012.

[58] J. Cox, S. Griffith, S. Giorgi, and G. King, "Consumer understanding of product lifetimes," Resour. Conserv. Recycl., vol. 79, no. 0, pp. 21-29, Oct. 2013.

[59] L. Hennies and R. Stamminger, "An empirical survey on the obsolescence of appliances in German households," Resour. Conserv. Recycl., vol. 112, pp. 73-82, 2016.

[60] "Postage Price Calculator." [Online]. Available: https://postcalc.usps.com/. [Accessed: 06Mar-2016].

[61] V. D. R. Guide Jr and J. Li, "The potential for cannibalization of new products sales by remanufactured products*," Decis. Sci., vol. 41, no. 3, pp. 547-572, 2010. 